\title{
LES DEUX VOYAGES DE F. PÉREZ BAYER AU PORTUGAL:
}

\section{2,1783}

Por M. H. PIWNIC

En 1768, Gregorio Mayáns écrivait à son correspondant portugais Manuel do Cenáculo, prélat érudit avec lequel il entretenait de solides relations d'amitié:

«D. Francisco Pérez Bayer, a quien toda mi vida he profesado una sincerissima amistad, a quien mi hermano $\mathrm{i}$ yo hemos intruido en quanto hemos podido, i a quien yo he facilitado los medios de conseguir el darse a conocer i de ser estimado, ahora es el que mas cruelmente me combate, o por mejor decir al Bien Publico». (1)

L'orientaliste Pérez Bayer, qui est alors précepteur des infants d'Espagne, fait en effet imprimer à Valence, poursuit Mayáns, une "Grammaire barbare des Ecoles Pies,(2) qui succèdent aux dénommés Jesuites dans l'art de capter les jeunes esprits. II est animé «de la diabolique ambition d'être le restaurateur des Lettres", imposant à l'église Métropolitaine de Valence quatre chanoines de son parti et faisant rejeter la juste candidature de Juan Antonio Mayáns, frère de D. Gregorio, dont les mérites sont notoires. En somme, conclut Mayáns:

"él i sus aliados, los descontentos por la expulsion de la Gente Social, los embidiosos i los ambiciosos de ser Maestros de la Nacion sin aver estudiado, me hacen una publica guerram.(3) 
Quelques années plus tard, lorsque Juan Antonio voit à nouveau lui échapper un canonicat vacant de la Métropolitaine, Mayáns estime que la faute en est imputable au même Bayer, qui a intrigué en faveur de son propre frère auprès de l'Infant Gabriel, et il s'en plaint derechef à Cenáculo. ${ }^{(4)}$

Pourtant Juan Antonio, après la mort de son prestigieux aîné, semble avoir oublié ces querelles. Cenáculo est alors évêque de Beja et lui écrit qu'il a eu l'honneur de recevoir chez lui "l'illustre Valencien D. Francisco Pérez Bayer»; il reçoit en réponse un éloge senti du bibliothécaire de Carlos III:

"No ha avido ninguno que aya tenido tan gran aparato para escrivir de las Medallas desconocidas Españolas",(5)

estime le frère de Mayáns. Bayer est si zélé, ajoute-t-il, qu’à son retour du Portugal, visité pendant plus d'un mois, son journal de voyage était déjà prêt, et qu'il a pu en donner lecture à diverses personnes de la Cour.(6)

Journal où l'on pouvait lire ce propos de Cenáculo, rapporté par le Valencien avec tout le respect dû à son compatriote:

"Hablóme de los Señores Don Gregorio Mayáns, Don Josef Climent, obispo que fué de Barcelona, y de Don Manuel de Roda, Secretario de Gracia y Justicia de Su Magestad: Todos tres difuntos en este año 1782, y exclamó: Que tres hombres!" (Diario, 119). (7)

D'ailleurs, Bayer ne proteste-t-il pas de son amitié pour D. Gregorio auprés de Juan Antonio, qu'il tient avec précision au courant de ses déplacements:

"Donde quiera, me ha acompañado inseparablemente mi afecto y gratitud que a V. M. professo y a la buena memoria del Sr. D. Gregorio (que haya gloria) y he tenido la satisfacción de ver a quán extendido está en Andalucía y Portugal el crédito de su gran literatura. Bien se persuadirá V. M. que nada perderia por mí que, además de publicar sus trabajos, su incessante aplicación, su discernimiento y crítica, etc., etc., añadía su gran zelo por el adelantamiento de nuestra literatura, su candor, su veracidad, su hombría de bien y lo irreprehensible de sus costumbres».(8)

Les difficultés paraissent donc aplanies avec le temps... Mais n'étaitce pas précisément parce que Cenáculo, ami de Mayáns, avait accueilli Bayer avec magnificence et le tenait en haute considération, en particulier parce qu'il était né dans ce pays valencien, que l'évêque de Beja aime à saluer son prestige culturel? "ll m'a parlé, dit Bayer, avec beaucoup d'estime de l'Université de Valence et du bon goût de ses professeurs, et comme je 


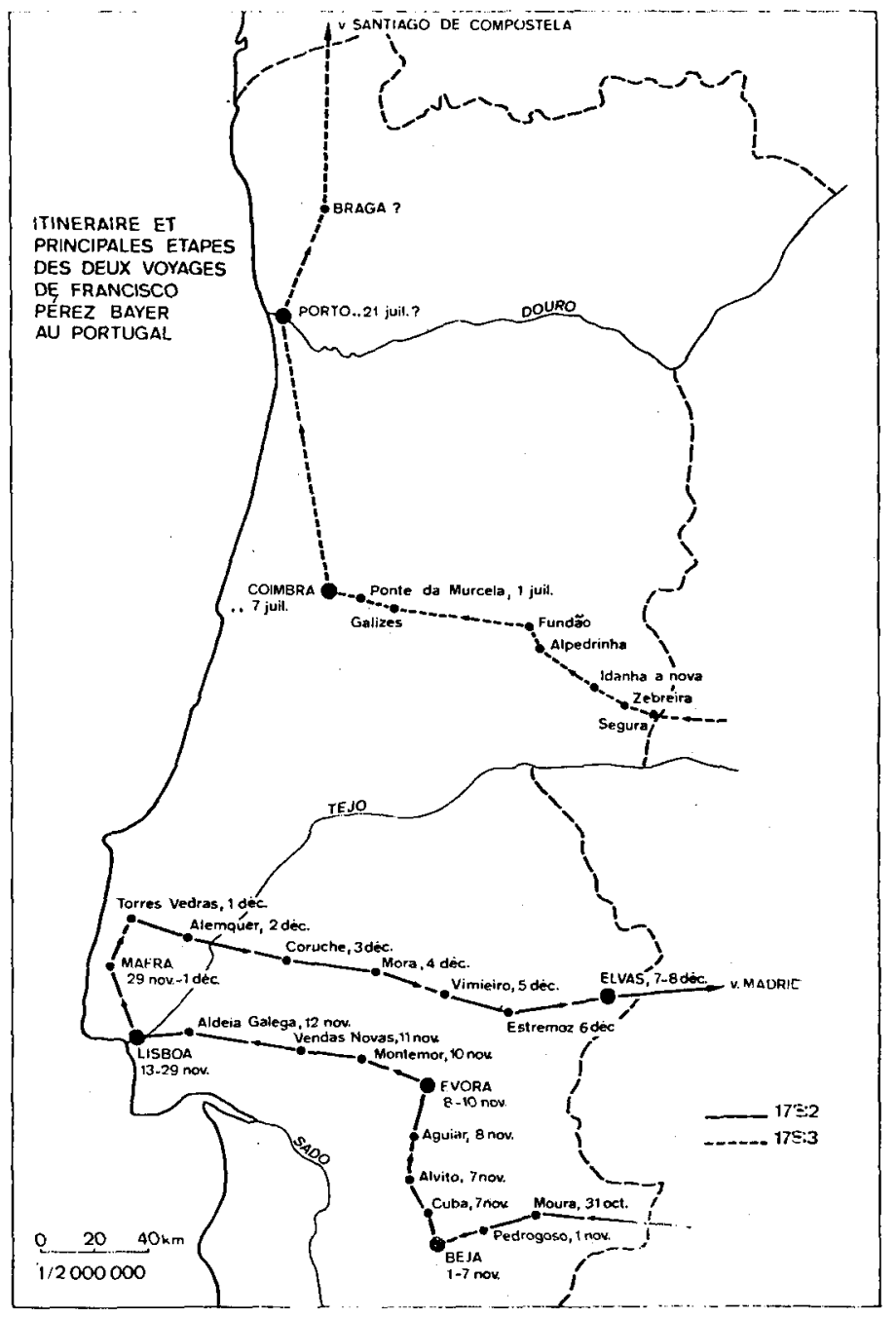

Les dates et les étapes du second voyage sont données à titre indicatif à partir des correspondances utilisées. Pérez Bayer écrit à Cenáculo de Ponte da Murcela le 1. juillet, puis de Coimbra-qu'il quitte alors selon ses dires-le 7 juillet. Le 2.1 juillet, J.-I. da Rocha Peniz fait savoir à Cenáculo que Baller est retenu à Porto, ses gens étant tombés malades. Bayer dans sa lettre du $11^{\circ}$ juillet indiquait à Cenáculo qu'il comptait voir Braga et se rendre ensuite á Santiago de Compostela pour la fête de l'apôtre; celle-ci se situant le 25 juillet, on peut penser qu'il renonça à ce dernier déplacement. Cenáculo lui écrit pour son anniversaire le 11 novembre 1783, le supposant "de retour dans sa patrie bien-animée, parmi les siens". 
le remerciais de la grâce qu'il me faisait à moi personnellement en cela, il m'assura que ce n'était que justice, due au mérite de notre Université, dont il avait lui-même fait l'expérience". (9) Dans une lettre à Juan Antonio, Cenáculo affine son éloge:

"Essa Universidade he muito habil para grandes e admiraveis progressos, porque os talentos Valencianos são agudos e naturalmente polidos».(10)

Bayer est l'un de ces talents subtils, et son compatriote ne va pas aller là contre, même s'il reste méfiant à l'égard de celui qui le rejoindra sous peu au banc des chanoines de la Métropolitaine: "on verra, dit-il à son correspondant portugais, ce qu'il nous apportera de concret, et de bon, des choses fort rares, pour ne pas dire invisibles par les temps qui courent". En attendant, le plan mis au point par Bayer avec Vicente Blasco pour l'Université de Valence mène celle-ci «à la ruine».(11)

Ce dernier trait donne à penser que pour le frère de Mayáns il y a, en somme, deux Bayer: celui qui va au Portugal en ambassadeur distingué de son pays et surtout de la province dont il est issu; de celui-lá il pense, ou en tout cas il dit le plus grand bien, négligeant les querelles mesquines, presques ménagères, qui les ont opposés. Et puis l'intrigant, qui a joué Madrid contre Valence pour assurer son ascension personnelle à un moment donné de son existence, mais n'a pas renoncé à exercer son emprise sur l'université de sa terre natale, non sans un désaccord important avec toute l'action des frères Mayáns. (12) Avec ce Bayer-là Juan Antonio est sur ses gardes, et n'en attend pas grand'chose de satisfaisant.

Cette perspective donne au voyageur un relief spécifique qu'il convient de souligner. Lorsque Francisco Pérez Bayer se rend au Portugal, il devient un personnage particulier, qui se dégage, aux yeux de ceux qu'il laisse comme dans l'esprit de ceux qui le reçoivent, des luttes d'influence si caractéristiques des Lumières espagnoles. II jouit d'une sorte d'immunité au profit de laquelle ses compatriotes oublient momentanément leurs ressentiments, épaulant en choeur sa mission, dont leur pays tout entier se trouve honoré. Ainsi les frères Mohedano, qui n'avaient jamais évoqué Bayer dans la correspondance qu'ils ont engagée avec Cenáculo depuis 1768 , mentionnent soudain avec sympathie le Valencien lorsqu'il se rend au Portugal: c'est un "lettré méritant", (13) et son oeuvre sur les monnaies est "très recommandable».(14)

Aussi faut-il considérer le voyage, au XVIII ${ }^{\ominus}$ siécle en tout cas, comme un moment privilégié dans les relations entre deux pays, peut-être plus significatif encore lorsqu'il s'agit de l'Espagne et du Portugal: les traditions d'hospitalité y ont de tout temps donné lieu à une surenchére, et l'on tient d'autant plus à s'y conformer que la rupture entre les Deux-Couronnes est consommée depuis plus d'un siècle, et qu'il y a donc lieu de faire assaut de politesse pour affirmer une entente désormais sans arrière pensée. 
Francisco Pérez Bayer accomplit deux voyages au Portugal. Le premier, qui fit suite à une mission archéologique en Andalousie effectuée à l'instigation de l'Académie d'Histoire de Madrid, se déroula du 31 octobre au 8 décembre 1782. L'érudit parcourut les régions à l'ouest de Badajoz et séjourna à Lisbonne, terminant par une visite de Mafra. Le second eut lieu au mois de juiliet 1783 et lui permit de visiter Coîmbre et son université réformée, ainsi que Porto. La date, 1782-1783, mérite qu'on s'y arrête. En effet Pombal est mort le 12 mai 1782, et sa disgrâce remonte à 1777. Si le Portugal tout entier porte encore sa marque, il n'en est pas moins vrai que le tableau esquissé par Bayer est à bien des égards sensiblement différent de celui qu'un Sánchez et un Mohedano brossaient dix ans plus tôt. (15) De plus, il semble que les deux expéditions Bayer aient donné l'exemple, en avivant une curiosité assoupie: Muñoz l'année suivante,(16) Cornide Saavedra un peu plus tard se rendront au Portugal pour en explorer les arcanes, avec des motifs scientifiques qui n'excluaient sans doute pas des intérêts moins avouables. (17)

Prendre la mesure de ces voyages espagnols au Portugal à l'époque des Lumières devrait amener à des confluences et à des divergences révélatrices, où le paramètre européen jouerait un rôle d'importance.(18) Mais mon propos se limitera aux périples de Bayer, sans doute les plus désintéressés de ceux que j'ai évoqués, et dont les témoignages sont parmi les plus riches et les plus objectifs. L'homme est à l'époque un personnage important à la Cour, qui s'est en particulier donné à connaître par ses interventions dans la réforme des Colegios Mayores, (19) et s'est vu confier par le monarque l'établissement d'un catalogue des manuscrits de l'Escurial. Quelque trente ans plus tôt, il a effectué un voyage en Italie sur instigation de Fernando VI, ce qui a largement contribué à l'enrichissement de sa profonde culture, où s'allient la connaissance des langues orientales et celle du latin. C'est un esprit curieux, un collectionneur inlassable d'inscriptions anciennes et de monnaies, un érudit pour lequel le passé historique de la Péninsule est du plus haut intérêt, cependant que la réalité contemporaine d'un pays frère est un constant sujet de réflexion.(20)

II nous informe au premier chef sur ses deux déplacements, d'une part avec le récit de son premier voyage, publié par l'érudit portugais Leite de Vasconcelos en 1920, auquel s'ajoutent trois lettres, également publiées, à Juan Antonio Mayáns, (21) et d'autre part avec un certain nombre de lettres inédites et toutes autographes conservées à Evora, à la Bibliothèque Nationale de Lisbonne et à la Bibliothèque de l'Académie des Sciencies de cette même ville. (22) II faut ajouter à ce précieux apport des lettres de Cenáculo,(23) ainsi que des passages de son journal intime, (24) des lettres de son secrétaire Vicente Salgado, (25) et quelques autres contributions. (26) L'ensemble de ces documents couvre les deux voyages.

Le texte du journal de Bayer, paru dans O Archeologo Português, a été 
établi par Leite de Vasconcelos à partir d'une copie en 100 folios du manuscrit initial, qui semble disparu, conservée à la Bibliothèque Nationale de Lisbonne. (27) II en existe une autre, en tous points identique, à la Bibliothèque de la Royale Académie d'Histoire de Madrid.(28) Toutes deux offrent la particularité d'être exemptes des dessins qui illustraient l'original, dont les copistes signalent l'existence par le mot falta. Or ces dessins, effectués par l'un des accompagnateurs de Bayer, que les Portugais jugeaient "fort habile", sont reproduits dans un beau volume, également archivé à la Bibliothèque de la Royale Académie d'Histoire de Madrid: Extracto de las inscripciones i otros monumentos antiguos que se encuentran en el manuscrito original que conserva la Universidad Literaria de Valencia, del Viaje literario que hizo a Andalucia y Portugal en el año 1782 el llmo. Sr. D. Francisco Perez Bayer del Consejo, y Camara de Su Majestad. Formado por encargo de la Real Academia de la Historia por su socio correspondiente D. Vicente Joaquín Noguera y Climent, y escrito por el Dr. Miguel Godinez Presbitero Beneficiado de la Metropolitana Yglesia de Valencia. (29) La partie portugaise du voyage occupe une trentaine de pages, toutes les indications subjectives ayant été éliminées. On peut en particulier apprécier un magnifique dessin du temple de Diane à Evora, ainsi que le pittoresque tracé de ces têtes de taureaux à propos desquelles Bayer intrigué évoque «les conjectures qu'Ambrosio de Morales fit à leur sujet" (Di., 116). II s'agit donc d'un complément indispensable par sa valeur historique et artistique à la publication de L. de Vasconcelos. Celle-ci, qui semble avoir été quelque peu oubliée, n'en est pas moins aisément accessible, aussi m'a-t-il semblé inutile d'en donner une relation linéaire, qui aurait, certes, collé à l'itinéraire autant qu'à la chronologie, puisqu'évidemment Bayer décrit dans l'ordre géographique et temporel les lieux qu'il traverse, mais offre une vision éparpillée des choses. J'ai remplacé cette évo. cation par une carte datée que l'on consultera en annexe, (30) à laquelle j'ai adjoint le tracé de la seconde randonnée, ayant résolu d'aborder dans le cadre limité qui m'est imparti les deux voyages sans solution de continuité, pour en donner un aperçu synthétique.

Bayer pensait d'ailleurs effectuer son tour du Portugal en une fois, et ce sont les intempéries de l'automne portugais qui l'obligèrent à renoncer à son projet initial de gagner le Nord aprés son séjour à Lisbonne, comme il le dit à Cenáculo:

«sepa V. Ex a que, ya que el año passado no passé a Coimbra desde las cercanias de Santarem, donde me hallaba en principio de Deciembre, à causa de las muchas Iluvias y de las cercanias de la Natividad del Señor, en cuyo tiempo tenia yo precision de hallarme en Madrid (...)m.(31)

Il abandonna sans doute pour la même raison l'idée un temps caressée de faire un crochet par l'Algarve.(32) Comptant revenir dès le printemps, 
il fut contraint par de graves ennuis de santé de remettre sa deuxième expédition au mois de juillet.(33)

La différence de climat entre l'Espagne et le Portugal est d'ailleurs un sujet d'étonnement et de préoccupation pour Bayer, qui y fait de fréquentes allusions. A Beja por exemple il ne peut sortir à cause du mauvais temps (Di., 119), à Beja encore il est obligé d'aller "se mettre à l'abri” chez le frère de Cenáculo (id., 118), à Beja toujours il parle de «l'air froid et pluvieux» qui le saisit (ibid.), et c'est au point qu'à Lisbonne, il doit se commander une toilette de rechange complète:

"Como no saqué de Valencia sino unos habitos de verano mui ligeros y comenzaba à apretar el frío fue preciso reponerme aqui de ropa talar como de camino" (id., 141).

En attendant d'être convenablement habillé, il diffère sa visite à l'Ambassadeur... (id., 142).

Même après s'être équipé, il a du mal à sortir certains jours dans la capitale portugaise, car il est difficile de trouver des chaises par mauvais temps, et il ne se risque donc, à pied, qu'au moment des éclaircies, chaussé de ses bottes et enveloppé de sa cape (id., 155).

Ces considérations météorologiques ont plus d'intérêt qu'il n'y paraît, car elles débouchent sur des réalités matérielles concernant les conditions du voyage. Pour le premier déplacement en effet -et probablement pour le second-, la petite troupe, qui compte sept personnes, circule à cheval et à dos de mulet, donc à découvert. On marche au pas, dans la mesure où l'on est chargé, y compris de provisions, et où deux des hommes de l'escorte sont à pied. Cette allure permet de parcourir normalement une lieue à l'heure. (34) Aussi comprend-on l'importance prise par la température et les précipitations. C'est ainsi qu'il pleut tellement au moment où Bayer quitte Lisbonne qu'il ne peut se rendre tout de suite à Mafra, la route étant devenue impraticable (Di., 162). De Mafra à Torres Vedras, les voyageurs avancent "dans la boue", et ce sont les "bourbiers et flaques" qui les dissuadent de remonter vers Coîmbre (id., 169). Ils manquent de se perdre, "ne trouvant personne à qui demander leur route, ni un morceau de terre labourée signifiant l'approche d'un village" (ibid.), craignent de devoir passer la nuit sous un arbre et, lorsqu'enfin ils parviennent à une auberge, font sécher leurs vêtements transpercés (id., 171). Jusqu'à la frontière espagnole, ils sont gênés par les pluies, mettent plus de six heures à parcourir les quatre lieues quil les séparent encore d'Elvas, car le chemin n'est plus carossable tant il est fangeux, et Bayer et sa suite arrivent "trempés comme des soupes" (id., 173). 
Les routes portugaises ne sont cependant pas l'objet de critiques de la part de Bayer, qui en fait même au contraire souvent l'éloge (35). "La route est bonnen, dit-il à plusieurs reprises à l'aller, de Befa à Evora, puis d'Evora à Vendas Novas (Di., 113 et passim), ce qui montre bien que l'état du ciel modifiait, selon qu'il était bon ou mauvais, l'appréciation que l'on se faisait du réseau. Or ces variations atmosphériques avaient de l'importance quand on cherchait une auberge, et Bayer préfère toujours s'arrêter avant la nuit, raccourcissant s'il faut son étape pour éviter les portes closes. II raconte ainsi qu'il a par deux fois été refusé dans des hôtelleries sur la route de Torres Vedras, où, dit-il, uon a fini par nous accepter pour l'amour de Dieu et de notre argent"! (id., 170). Son attitude à l'égard des auberges portugaises est d'ailleurs, hormis ce détail d'ordre climatique, bienveillante dans l'ensemble.(36) A Lisbonne, où il s'installe à la "Posada de la Estrella, en face de San Benito, l'une des plus réputées» de la capitale, bien qu'elle soit un peu loin des commerces, on lui donne à manger "d'excellente façon", et il a "une chambre confortable, au sud, bien éclairéen. II la quitte cependant car il ne peut y loger ses montures, s'étant renseigné sur les auberges les plus distinguées de la ville, et qui soient centrales; on lui conseille "la Piamontesa, rua nueva de Almada, en face de l'église de la Concepción Nueva", où il obtient une chambre "très confortable et bien éclairée; il y prend toujours ses repas, ne descendant jamais à la table d'hôte (Di., 143-144).

On doit penser, à ces quelques détails, qu'il en fut satisfait. Et s'il dispense de tout commentaire les autres établissements où il se loge tout au long de sa route, tant à l'aller qu'au retour - sauf un, dont il apprécie le feu de cheminée (id., 172) - c'est probablement qu'ils étaient honnêtes: il prononcera en effet tout de même les mots malissima posada, à Mora, ajoutant qu'il a appris ensuite qu'il aurait pu au même endroit être décemment logé.

D'autres voyageurs étrangers se sont montrés nettement plus réticents... Mais les auberges espagnoles n'avaient pas bonne réputation, et peut-être Bayer se choque-t-il moins facilement du manque de commodité qu'un Anglais ou un Allemand. (36)

Il n'évoque qu'une seule fois la nourriture servie, précisément parce qu'elle est mauvaise:

"Comimos infelizmente porque ni havia huevos (ni los hallamos en Moura) ni pescado, ni judias, ni fruta, ni cosa alguna. La dueña de la casa donde nos albergamos (porque tampoco hay mesón) nos guisó un arroz que parecian puches". (Di., 113). 
Il écrit cela le deuxième jour de son entrée au Portugal et ne fera plus jamais une remarque sur le ravitaillement dans les auberges, alors qu'il note avec soin qu'il a pris son déjeuner, son dîner, etc., ce qui conduit nouvellement à penser qu'il le juge dans l'ensemble convenable, d'autant que ce savant est un homme gourmand, trés attentif aux entremets, desserts, sucreries qu'il consomme chez les particuliers (Di., 130). II a même une passion immodérée pour le chocolat, dont il fait mention presque chaque jour, parfois à deux ou trois reprises, et qui est aussi sa façon d'être frugal, puisqu'il s'en contente parfois pour tout potage avant d'aller au lit. Plus tard, à Madrid, il donnera dans une lettre à Cenáculo la clé de cette apparente contradiction:

"tengo un amor grandissimo a la pobreza (...) y me parece que tuviera grandissimo deleite en pedir limosna, y en passar algun hambrejoncillo y algun frio; y en rebujarme en un rincon con mi capote; quando ahora duermo en blando y arropado; me dan caldito y chocolate a su hora (...) pero sabe Dios que no desfruto estos bienes, ni llego bocado a mi boca que no me acuerde de tantos y tantos pobres como havrá (...). Con estas especulaciones esteriles (...) parece que me consuelo y sossiego; que sé yo si llegado el caso de haver de dejar mi chocolatito, por ejemplo me haria proferir mi gula (...) charitas a semel ipso o cosa asi».(37)

Ce upetit chocolat», puisque chocolat il y a, il arrive qu'on ne le fasse servir que pour lui, ainsi lors d'une réception donnée en son honneur à Evora par un ami de Cenáculo, le notable José Maldonado:

«Sirvióse un refresco decente de thé con vizcochos (que és el estilo del País) y chocolate el que se añadió por mi respeton (Di., 136).

En somme, n'était le climat inhabituel, et contrariant, le voyage matériel au Portugal se fait dans des conditions satisfaisantes, seion les dires, ou les silences de Bayer. S'il pense un jour sa sécurité menacée, c'est à la suite d'une erreur: cherchant sa route, il est pris pour un contrebandier par le cavalier qu'il interroge et qu'il imagine, lui, être un détrousseur. II conte plaisamment le quiproquo; l'homme entend parler de cargas - Bayer lui signifie qu'ils vont trop vite étant donné leur chargement - et se convainc qu'il a affaire à des passeurs en douane peu orthodoxes. Il feint donc de ne pas trouver sa route, et Bayer y voit un signe inquiétant: il doit s'agir de quelque malandrin. Avec beaucoup d'à-propos, il le fait encadrer par ses trois hommes en selle, fusils chargés, leur ayant donné ses ordres en valencien pour ne pas être compris de ce peu rassurant guide. L'autre n'en est que plus inquiet, et il lui faudra la promesse renouvelée d'un bon pourboire pour qu'il consente à accompagner les voyageurs jusqu'á leur point 
de destination, Coruche, après avoir découvert son identité, celle d'un garde forestier du roi, avouant enfin que le langage tenu par Bayer aux siens dans un idiome inconnu avait porté au comble sa frayeur. Le Valencien, pour sa part, affirme qu'il n'aurait pas hésité à employer la force (id., 169171). L'anecdote, toute divertissante qu'elle est, n'en témoigne pas moins du danger que l'on encourait lors de telles randonnées, que l'on effectue armé, et souligne un rapport linguistique intéressant. Le garde, s'il a mal interprété l'allusion au chargement, a parfaitement compris ce que Bayer lui disait en espagnol. En revanche, il n'a rien compris aux propos en valencien...

Les problèmes douaniers retiennent aussi l'attention de Bayer; ils se résolvent sans trop de mal, mais toute une série de formalités précises régit le passage de la frontière et les déplacements au Portugal. Le voyageur a le mérite d'y avoir attaché suffisamment d'importance pour nous en laisser un témoignage détaillé. II recopie en effet le laissez-passer qui lui est remis à Moura, où est consigné le nombre de montures qui l'accompagnent, soit trois mulets et trois chevaux selon le document, et aussi la fiche signalétique qui est établie à son sujet par le secrétaire des douanes, qui ébauche ainsi un véritable portrait de l'érudit:

"Don Francisco Pérez Bayer Espanhol Cavalleiro da Ordem de Carlos III de Espanha de idade 70 as estatura alta, cara comprida, ollos pardos, cabello russo/barba o mesmo, trigueiro dorado (o colorado) etc." (Di., 111-112)

prenant note aussi de la composition de l'escorte, dont nous n'avons connaissance, nous, que par le journal de Cenáculo:

"(Bayer) tras tres creados de baixo e dois de cima e hum dezenhador».(38)

Le laissez-passer est établi pour deux mois au vu du passeport(39) et n'est remis à Bayer qu'à l'expresse condition qu'il renvoie depuis Lisbonne une sorte de contre-laissez-passer, muni des cachets nécessaires (Di., 112). Pour ce faire il doit se présenter immédiatement à l'Ambassadeur (id., 141).

Le déménagement d'une auberge à l'autre dans la capitale faillit à ce propos créer un petit incident. En effet, on vint contrôler les passeports et laissez-passer de sa suite, restée au premier endroit choisi, après que Bayer a quitté les lieux. L'aubergiste, semble-t-il, n'avait pas déclaré les voyageurs, et manqua d'être fait prisonnier (id., 143).

Bayer, lui, est soucieux de régularité, et demande donc à la Mesa Censória (40) les autorisations nécessaires pour expédier les livres anciens dont il a fait l'acquisition. Celle-ci les délivre au nom du roi, et les Douanes n'accordent le sauf-conduit aux muletiers que sur présentation de ces autorisations (Di., 156). Le voyageur n'oublie pas non plus les douanes espagnoles, 
et renonce à acheter des soieries et des cotonnades indiennes et chinoises par crainte d'enfreindre les lois protectionnistes adoptées par son gouvernement (id., 155).(41) II semble qu'il se soit laissé aller à moins de rigueur en apprenant qu'il pouvait faire transiter ses achats par l'Ambassade d'Espagne et jouir alors de l'immunité diplomatique (id., 156).(42)

C'est évidemment en homme pratique, délibérément inscrit dans un siècle positif et rationnel, que F. Pérez Bayer confie à un journal qu'il compte rendre public(43) ces menues notations matérielles: temps qu'il fait, durée des étapes, état des routes, nourriture, logement, contraintes administratives.

Sans l'avoir vraiment voulu, il nous permet aussi par des indications éparpillées quelques réflexions sur les dépenses occasionnées par son premier voyage, qui sont corroborées par les autres documents dont nous disposons. Par hasard, par chance pour nous, il déclare à un moment donné le taux de change pratiqué à l'époque entre les monnaies espagnole et portugaise. Cenáculo, qui le reçoit à Beja, vient de lui montrer un ouvrage ancien; il s'agit de la Biblia Moguntina, de Juan Fust et de M. Schoiffer de Gernsheim, un superbe manuscrit de 1642 realié en vélin, "gardé comme un trésor dans une boîte doublée de maroquin»:

"me aseguró haverle costado setecientos mil reis, (44) que son casi otros tantos maravedis, e más: Yo hice juicio que le costaria como mil y trescientos pesos de Castilla de á quince reales y dos maravedis cada uno. Es alaja digna de un Príncipe" (Di., 123).

Les réis portugais, nous dit donc Bayer, sont à peu près l'équivalent des maravedis espagnols. Depuis 1772 et par pragmatique, le réal espagnol valait 34 maravedis. Si donc le maravedi et le real portugais sont quasi égaux, on peut estimer le réal espagnol à 34 réis portugais. Et c'est bien en effet le chiffre auquel on arrive en divisant le chiffre de 700.000 réis portugais coûtés par la Bible que Bayer examine par le nombre de réaux espagnols impliqués par le montant des pesos de Castille qu'il donne (1300 x $15,2=19.760$ ), soit $700.000: 19.760=35,4$ réis portugais pour un réal espagnol.

Ce dernier chiffre me servira de base dans l'appréciation des autres données èvoquées par Bayer ou les interlocuteurs de son voyage.

II semble en effet qu'il ait décidé soudainement de passer par le Portugal (Di., 120), ce qui supposait l'engagement de frais personnels, seul le voyage en Andalousie ayant fait l'objet d'une mission de l'Académie d'Histoire de Madrid. L'on s'explique alors que l'équipement du groupe n'ait pas été prévu en conséquence, et que le budget primitivement établi ait été insuffisant. C'est ainsi que Bayer emprunte à son arrivée à Lisbonne au beau-frère de Cenáculo, António Duarte Réis, deux fois 40.000 réis, soit 
2.260 réaux; et l'on apprend à cette occasion que la première moitié de cet argent est destinée à régler une dette contractée auprés d'un gentilhomme de Beja:

"Aqui en la casa de la Sra Hermana de V. Exa me visten y me dan dinero para quanto se me ofrece, y pueda ofrecer en esta Capital y en mi viaje, y creo que me darian tambien de comer de buena gana si le necesitasse. El Sr. Don Antonio Duarte hà satisfecho por mi los 40 . mil Reis que aí tomé, y de que va el recibo a favor de esse Cavo Governante. Mañana tomaré otros 40.mil Reis para lo que aqui se me ofrezca».(45)

II s'est donc senti très rapidement démuni au Portugal. Sans doute la magnificence des réceptions données en son honneur et la munificence de Cenáculo le conduisent-elles à un rythme de retour, au plan des pourboires, des cadeaux, supérieur à ce qu'il avait envisagé: à Estremoz, à Elvas, il fait allusion aux gratifications conséquentes qu'il dispense aux troupes qui lui rendent les honneurs ou sont prévues pour l'accompagner (Di., 172-174).

On a vu qu'il use de largesse auprès du garde forestier pour le dissuader de ses fâcheuses conjectures. Dans cette mesure aussi, il se doit de loger dans les auberges les plus cotées, donc les plus chères on l'a remarqué, de même qu'on a dit la nécessité dans laquelle il s'était trouvé de se faire faire une tenue d'hiver complète, pour tenir son rang, selon Salgado. (46)

Mais surtout, il fait des achats. De librairie, comme je le signalais plus haut. De frivolités aussi, "pour les amis de Madrid et de Valence" (Di., 151155): hormis les tissus, des foulards, babioles des Indes, (47) taille-plumes (ibid.). Il est très discret sur le montant de tous ces frais dans son journal. Une seule notation concernant les livres; après une première visite à deux libraires de Lisbonne, il écrit que ses acquisitions de bibliophile "n'ont pas été chères" - 432 réaux, alors qu'en Espagne il y en aurait eu pour milleet que «l'on n'auraił d'ailleurs peut-être pas trouvé les livres en question, devenus très rares" (id., 145). Sur la base que j'ai déduite de Bayer luimême, soit un real espagnol $=35,4$ réis, on est conduit au chiffre d'une dépense de 15.292 réis. Mais il déboursa des sommes autrement plus importantes. Remerciant l'évêque de Beja pour "la mine inépuisable de ses bienfaits", il lui écrit avoir acheté pour 260.000 réis de livres, (48) soit à peu près 7.340 réaux! D'autre part, Vicente Salgado, secrétaire de Cenáculo, écrit à son évêque le 25 novembre:

"Hoje foi buscar dinheiro (il s'agit de Bayer) e amanhã diz que paga. Entre livros e tudo importa quatro centos e oitenta mil reisn. (49)

Le total, s'il est exact, est cinq fois supérieur au premier emprunt! Et 
revient à 13.559 réaux espagnols et quelque, soit 892 pesos de Castille ou 678 pesos fuertes. Si l'on songe au salaire d'un journalier à l'époque en Espagne, 6 réaux par jour, (50) on est impressionné, mais on l'est aussi si l'on pense qu'en 1785, un magistrat de la Audiencia avait 18.000 réaux par an,(51) et que les emprunts de Bayer, dont le journal ne souffle mot, représentent les $2 / 3$ de cette somme, rendant probablement compte à peu près du coût total de son séjour au Portugal.

On peut se demander par ailleurs si ce chiffre de 7.340 réaux consacré aux livres peut être mis en parallèle avec la première dépense, ces 432 réaux dont il dit qu'ils auraient été multipliés par deux pour les mêmes ouvrages en Espagne. Que signifieraient les prix plus bas pratiqués au Portugal? J'aurais tendance à en conclure à un marché plus ouvert et plus concurrentiel, ce qui ressort de la lettre bien connue de l'imprimeur français Boudet.(52) Bayer était en tout cas un expert, trouvant chère, par exemple, la Bibliotheca maxima Veterum Patrum completa avec les deux tomes de l'Apparatus de Nourri, qu'on lui propose à 5.400 réaux, mais achetant pour 90 pesos (soit 1.368 réaux), après avoir marchandé, la Biblia Regia d'Arias Montano, qui lui était offerte à 100.

Le secrétaire de Cenáculo était un peu irrité du faste de Bayer, mais le crédit de ce dernier ne fut jamais mis en doute, d'autant moins que l'Ambassadeur s'était porté garant. (53) D'ailleurs Salgado lui-même dit:

"Confiamos na honra e proceder de Bayer posto que ainda se não ajustou o modo de se embolçar, em que não haverá dúvidan. (54)

Il faut dire que l'orientaliste était un homme riche, qui allait l'être plus encore après que Carlos III l'eut choisi comme bibliothécaire. Il écrit en effet à Cenáculo en 1784:

"aunque me há dado (le roi) y dá abundantissimamente con que vivir de suerte que mantenida mi casa y familia con decencia y esplendor, y aun con arbitrio para hacer algunas limosnas del sobrante de mis sueldos, tengo en Valencia de mis prebendas, annuos 10.000 pesos fuertes e 200.000 reales de rentan., (55)

II put donc se permettre de ne pas être en reste avec les Portugais, et en particulier avec la généreuse hospitalité de Cenáculo. On est frappé d'autre part par la tranquillité avec laquelle Bayer se rend au Portugal ensomme sans argent, et aussi par les facilités qui lui sont offertes afin qu'aucun problème matériel ne le gêne. Sans qu'il le dise, on peut raisonnablement penser qu'il halla aussi à Beja parce qu'il pensait trouver auprès de Cenáculo une solution de financement.

Le voyage de Bayer, dont j'ai voulu donner une idée concrète parce qu'on n'attache souvent pas assez d'importance à ces détails quotidiens, 
présente, bien sûr, quantité d'aspects d'une tout autre nature, auxquels je m'attacherai maintenant.

II signifie d'abord peut-être au premier chef la rencontre avec un homme d'envergure, Manuel do Cenáculo Vilas Boas. (56)

Né en 1724, le futur archevêque d'Evora fait une carrière brillante après un voyage à Rome, en premier lieu au sein du Tiers-Ordre Régulier de Saint-François, dont il est d'abord le chroniqueur, puis le Provincial et Définiteur Général, mais aussi à l'échelon national: confesseur et précepteur de l'Infant D. José, président de la Real Mesa Censória, de la Junta do Subsídio Literário, (57) premier conseiller de la Junta da Providência Literária(58) et enfin évêque de Beja (1770). Son ascension se voit momentanément freinée par la mort de José l et la disgrâce de Pombal, mais la puissante personnalité de Cenáculo lui permet, après qu'il a pris possession de son diocèse -où il est astreint à résidence en 1777- de réaliser une oeuvre que l'on peut qualifier d'admirable.

A Lisbonne déjà il avait fait du Couvent de Jésus une école réputée pour les enseignements d'arabe, de grec, de syriaque et d'hébreu qui y étaient délivrés, toutes langues que lui-même a étudiées et lit; il a formé des professeurs pour l'Université de Coïmbre, présidé à des éditions en caractères orientaux, ${ }^{(59)}$ commencé à constituer une bibliothèque. ${ }^{(60)}$

A Beja, il déploie ses activités sur de multiples registres: soucieux d'organiser les études des séminaristes et de réformer la discipline sacramentelle et la catéchèse; accordant à l'action épiscopale une place essentielle à la fois théorique par le recours aux pastorales, et pratique par les visites aux fidèles et aux établissements de réguliers; gardant enfin à l'érudition une place d'honneur par la créaction d'une bibliothèque impressionnante, et d'un musée épigraphique et numismatique estimable.(61)

La renommée de Cenáculo avait franchi la frontière espagnole depuis fort longtemps. En 1768, en effet, au Chapitre de son ordre, tenu à Valence, il avait ouvert la session avec une oraison latine improvisée qui avait subjugué les esprits par son brillant, et dont Bayer a pris connaissance:

«Havia yo venido a esta Ciudad de Beja (...) no tanto por sus memorias Romanas (...) como por conocer y tratar al Illmo. Señor Don Fray Manuel del Cenaculo, Obispo de ella, Religioso Franciscano de la Orden Tercera, sugeto de gran credito en todo genero de literatura, de quien havia yo leido algunos opusculos, y entre ellos la Oración Latina Eucharistica, que dixo casi de repente en el Capitulo General de su Religión tenido en Valencia mi Patria los años pasados de 1770, o por ai" (Di., 113).

Reçu alors avec tous les égards par Mayáns, le Portugais entretint ensuite une correspondance suivie, pendant plus de vingt ans, avec le gran 
Valencien. (62) D'autre part, son élection à la Définition Générale à ce même chapitre avait mis l'Andalousie sous sa juridiction, et les frères Mohedano lui écrivent régulièrement. Après le séjour à Lisbonne de Rafael, Cenáculo garde au Couvent de Jésus le jeune José Banqueri, futur traducteur du Livre d'Agriculture d'Abu Zacharia Ebn el Awwam, afin de le perfectionner en arabe, et un certain Pedro Jiménez, qui étudie l'hébreu, cependant que deux autres séminaristes grenadins, Juan Pérez de Luque et Domingos Herrera se rendent plus tard à Coîmbre sur sa recommandation pour y étudier respectivemente les Mathématiques et la Physique Expérimentale. (63)

Orientaliste, passionné d'archéologie et de numismatique, bibliophile, homme d'idées éclairées, Cenáculo n'est-il pas une sorte d'alter ego de Bayer lui-même?

En tout cas, une amitié spontanée naît entre les deux hommes, entre cet Espagnol de haute taille, aux yeux gris, au poil roux, au visage allongé, qui va avoir soixante-et-onze ans, et ce Portugais de cinquante-huit ans, petit et vif, au regard sombre, aux cheveux noirs. (64) Bayer, qui s'est dévié de la route normale de Lisbonne pour emprunter un mauvais chemin, uoù les voitures ne peuvent passer" (Di., 113), attend d'abord quelques jours, car Cenáculo est en visite pastorale dans la région d'Ourique; il prend patience en arpentant Beja et en recopiant des inscriptions sépulcrales. Cenáculo, prévenu par son frère de l'arrivée du Valencien, (65) le rejoint bientôt et l'accueille avec chaleur. L'enthousiasme réciproque dont ils sont touchés les entraîne dans des conversations passionnées sur de grands sujets, et ils ont du mal à se quitter, au soir de leurs échanges, par exemple sur les méthodes d'études. "Nous n'arrivions pas à nous séparer", écrit Bayer, qui ne cache pas son admiration pour Cenáculo:

"Confieso que aprendí muchas cosas, y que huviera dado gustosamente lo que más estimo en este Mundo por que huvieram oido a este Docto y Zeloso Prelado algunos de las principales Iglesias de Españas (Di., 126).

II apprécie tout spécialement "la solidité de ses principes", sa "clarté d'expression", et approuve pleinement sa conception du rôle d'un évêque, qui doit estimer et aider son clergé, surtout ses prêtres, parce qu'ils sont à la base de l'éducation des personnes, elle-même ciment des progrès des Arts, des Sciences, du Commerce, de l'Agriculture. Quan poco hai de esto en el Mundo! conclut Bayer (ibid.).

L'évêque de Beja, de son côté, confie à son journal:

"(Bayer) he tal sogeito qual se ve nos seos escritos e dis a sua fama. Le bem todo o antigo, sabe hebreo, grego, arabe etc. Singularissimo humanista (...) Conversamos infinitamente et não começamos a fallar. He muito homogeneo comigon..(66) 
"Il se déplace à cheval, et marche aussi beaucoup à pied", ajoute-t-il, car malgré son âge, il est "solide comme un roc et plein de vaillance».(67)

Outre l'activité archéologique qu'il déploie en ville, accompagné d'un antiquaire distingué, auteur d'une Chorographie de l'ancienne Lusitanie et d'une Histoire de Beja, Felix Caetano da Sylva,(68) Bayer se voit ouvrir les portes de la collection personnelle de Cenáculo. Diverses inscriptions anciennes en provenance de Lisbonne sont en effet dignes d'intérêt. Elles sont encore dans des caisses? Qu'à cela ne tienne! On décloue les caisses, et Bayer peut recopier tout à loisir (Di., 127). Au total, il relève quelque vingt-trois inscriptions au cours de son séjour dans la ville épiscopale, ${ }^{(69)}$ moisson qu'il complètera à Evora, avec onze inscriptions dont huit, note-til, sur la Plaza Mayor de la ville, placées sur une fontaine au temps de Philippe III, roi d'Espagne et de Portugal (id., 139).

Traité en connaisseur, il est invité à ce titre à juger des réalisations de Cenáculo. II reconnaît d'abord la bibliothèque publique instituée par l'évêque de Beja pour ses futurs ordonnés et les éventuels curieux qui seraient intéressés.

C'est une pièce de moyennes dimensions, qui

"abunda en Libros de Humanidad, Philosophia, Teologia en todos sus ramos, Disciplina e Historias Eclesiasticas, Liturgia, Ritos Sagrados, Catecismo, y todo lo que puede contribuir a que se crien buenos Párrocos. Hai también Libros de eloquencia espesialmente sagrada para Predicadores. Algo de Historia profana, Griega y Latina antigua y moderna" (Di., 121-122).

Elle est située dans le palais épiscopal lui-même, ce qui la rend commode à fréquenter. Mais ce qui intéresse le plus Bayer, évidemment, c'est la librairie personnelle de Cenáculo qui comprend, elle, trois pièces spacieuses, entièrement tapissées de livres, avec même des étagères mobiles au milieu de l'une d'entre elles. II y apprécie de nombreuses collections, placées dans les deux premières pièces, en particulier les actes et mémoires de diverses académies, les Pères de Saint-Maur, des éditions anciennes, les meilleures éditions des Poètes, Orateurs et Historiens grecs et latins etc. «En résumé», dit-il, "tout ce qu'on est en droit de trouver dans les bibliothèques les plus choisies et les plus érudites» (ibid.). Dans la troisième pièce sont conservés des manuscrits de grande valeur, Bibles, Livres ecclésiastiques divers, parmi lesquels il remarque, on s'en doute, ceux qui sont en traduction castillane:

"Entre los manuscritos me enseño cinco tomos en folio, en vitela, traducción castellana del Chronicon de Eusebio Cesariense hecha por el Señor Alonso de Madrigal o el Tostado, tan bien conservados como si acabaran hoi de escrivirse: letra hermosisima y acaso del tiempo de su insigne Traductor. En la pri- 
mera pagina tiene el primer tomo un Escudo de Armas iluminado, sostenido de dos Angeles (...) Es obra digna de un Monarcan (ibid.).

Ainsi du Nouveau testament avec la version castillane d'Encinas, de la Bible Hébraïque et Espagnole récemment imprimée à Amsterdam, "et autres raretés dont il est facile de se souvenirn (id., 123).(70)

L'évêque de Beja lui dit faire venir de Madrid tout ce qui s'y publie,(71) et Bayer le plaisante alors sur un opuscule anonyme publié à Madrid l'année précédente, et dont il doute que Cenáculo le connaisse, car l'auteur en a fait retirer les exemplaires à la suite d'un différend avec un ami. Auteur qui n'est d'ailleurs pas un inconnu de son interlocuteur, loin de là:

"Tanto dixe a su lllma que entró en gran deseo de saber quien era, y mas con que le havia dicho antes que era su amigo. No quise explicarme mas, solo añadi que era sugeto enciclopedico: que havia escrito de Cimbrios, Lombardos y Godos: Nombróme su Illma a algunos y me le nombró tambien pero yo no quise jamás declararme» (Di., 121).

On conclut de tous ces mystères qu'il s'agissait probablement de Campomanes, en effet correspondant de Cenáculo et lié à lui de bonne amitiè. (72)

Ce sont aussi les tableaux qui ornent le palais qui retiennent l'attention de cet érudit éclectique qu'est l'antiquaire valencien. II est très sensible à une toile de l'Espagnolet, à deux du Bassan, et à un caprice dû à un peintre portugais

"llamado N. Vris con su firma. Esta pintura me pareció insigne, aúnque no lo entiendo ni puedo dar la razon porque» (Di., 127). (73)

A Evora, peu après, il trouvera plaisir à contempler le retable de la cathédrale dû à Agostino Massuci, un peintre italien dont il a fait la connaissance à Rome en 1755 (id., 132).

Bayer examine aussi le Médaillier. (74) Sa compétence dans le domaine numismatique stupéfie ceux qui le recontrent, et Salgado écrit de Lisbonne à Cenáculo:

"Na verdade he hũ homem. De medalhas que viu (...), pasmava a gente da velocidade com que estando nas mesmas taboas dizia: Esta hè falsa, esta he boan.(75)

A Beja, il tombe en arrêt devant une pièce rare, et cette marque d'attention donne lieu à la scène qui suit, si caractéristique de la cordialité portugaise encore aujourd'hui, et qu'il rapporte avec saveur: 
"Pedile a su IIIma me la permitiese copiar. Tomola, y pusola en mi mano, y me dixo: Tibi habeto: y no se hable más, y 10 mismo (añadió) de qualquiera otra, ó de qualquier libro que haya al proposito de Vmd ó le guste: por que aúnque estas cosas (prosiguib) son las de que yo hago el mayor aprecio en este Mundo sé tambien privarme de ellas en obsequio de un amigo, que conozco hará mejor uso que yo" (Di., 123).

La conversation avait-elle lieu en espagnol? On peut se le demander sur cet exemple. Quoi qu'il en soit, Bayer prend la médaille en toute simplicité, car, dit-il, "son lllustrissime n'en avait pas besoin, et à moi elle peut être utile..." (ibid.).

On le voit, une intimité vraie, une mutuelle confiance appuyée sur une estime réciproque régissent très vite les rapports entre ces deux fortes individualités, et Bayer n'hésite pas lorsque son hôte, qui est amateur de musique, lui offre un concert avec le ténor italien José Todi, (76) à prendre le violon et à exécuter un morceau de façon improvisée:

"pedi un violin y vuelto a Su IIIma le dixe que en su obsequio (...) haria una travesura, y veria si me acordaba de lo que havia aprendido en mi juventud. Pusieron una simphonia cuyo primer allegro tenia bastante execución; confesé que estaban ya mis dedos torpes para tanta nota. Dexé que se tocase el allegro, toqué el adagio y el segundo allegro, previniendo el Maestro de Capilla que no fuese mui corrido. Sali en fin de mi empeño y quando se concluyó dixe a Su IIIma ...semel insanivimus omnes" (Di., 129).

Plus tard, il accompagne un aria, à la demande expresse de l'évêque, et se "sort sans dommage de l'entreprise" (ibid.). Cenáculo note dans son journal:

"Como elle (Bayer) he muito curiozo de musica, inflammou-se: tomou hum violino e acompanhoun. (77)

L'évêque de Beja, après leur rencontre, placera encore davantage le voyageur sous son aile tutélaire tout au long des deux randonnées de celui-ci, prévenant par lettres ses proches, sa famille, ses amis, du passage de "l'illustre Valencien", au point qu'on a parfois l'impression que Bayer avance au Portugal telle une mouche prise dans l'invisible toile d'araignée des relations de Cenáculo. II est attendu d'une ville à l'autre, des courriers transmettent ses déplacements, d'autres rapportent les nouvelles de ses différents séjours. ${ }^{(78)}$ Choyé, comblé, accueilli par des plateaux couverts de douceurs, ou invité à écouter un musicien en visite, (79) il est comme porté tout au long de sa route, et cela jusqu'à Coïmbre,(80) au point d'en éprouver parfois quelque lassitude, ou quelque gêne, qu'il laisse discrètement percer: 
"En la Cuba, en Ebora, y aqui me persiguen, honrandome mucho los favores de V. Exa . Quo ibo, aut quo a spiritu tuo fugiam? Aqui he hallado al Rmo P. Salgado con otros dos Sres que se han querido incommodar para prevenir mi alojamiento: he hallado comida prevenida y transito o embarcacion para êl; en la Cuba postres exquisitos de que hé comido asta hoi: en Ebora los Sres Aguilar y Maldonado y otros á su exemplo me han confundido con sus expresiones y finezas. Sê lo que me espera en Lisboan.(81)

A Evora, en effet, le notable Maldonado, mais aussi les dignitaires de la cathédrale, ainsi que l'archevêque et l'inquisiteur de la ville, s'ingénient à lui montrer les beautés de l'ancienne Liberalitas Julia. Il a ainsi le loisir d'apprécier l'église de San Francisco, (82) «magnifique, avec un portail gothique remarquable» (Di., 131), dont la chapelle aux colonnes faites d'ossements humains ${ }^{(83)}$ impressionne défavorablement son bon goût:

"Lo más estraño és que dos ó tres esqueletos que se conservan casi enteros y con su piel acartonada estan en un angulo de la capilla atados como se ata un haz de leña, y colgados sin tocar, como dicen en Cielo ni en Tierra. Confieso que á mi me chocó el tal espectaculon (id., 132).

En lui montrant la cathédrale, on lui pose des questions sur les églises de Tolède, Séville et Valence, dont on souhaite connaître les richesses et l'importance du chapitre à des fins comparatives. Le presbytère, qui date de Jean $V$, lui paraît de bonne venue, mais il s'arrête plus longuement dans la chapelle du Santo Leño de la Cruz, estimant que le Christ en est peut-être plus grand que celui du Monastère de San Miguel de los Reyes, (84) et laisse une description prolixe de la riche custode. (85) Non loin du temple de Diane, il admire le Couvent de Lóios. (86) Invité à contempler la Tour de Sertorius, qu'on lui affirme dater des Romains, (87) il commente avec humour:

"La Torre ni es del tiempo de Sertorio, ni lo piensa, ni tiene de quinientos años arriba. Dixelo assi; pero el Padre se mantenia con su Sertorio. Yo dixe entonces que era tan Sertoriana como la Universidad de Huesca en Aragón. Quiso Dios que no me entendió antes bien la tomó por concedida, y añadió: essa abertura que tiene (está hendida de arriba abajo) se cree que sea del terremoto que huvo quando murió Nuestro Redemtor en la Cruz. No me pareció sacarle de su buena fée ni lo huviera logrado, y assi callé y quedamos amigos" (Di, 134). 
Enfin, il n'oubliera pas de rendre hommage à l'antiquaire André de Resende en sa maison, et on l'entraînera même jusqu'au monastère des Chartreux (88) - bien moins grand que ses homologues espagnols, dit-il一, dans les environs de la ville, pour lui montrer des manuscrits, qu'il trouve estimables sans plus (Di., 135).

Tout au long de ces deux jours, l'ombre de Cenáculo plane sur ses rencontres, sur les honneurs dont il est l'objet, comme il le souligne lui-même. Et s'il ne prévient pas l'évêque de Beja de son second départ et ne l'avertit de sa présence qu'à quelques kilomètres de Coïmbre, c'est parce que, l'année précédente, celui-ci avait tant "révolutionné, et, à dire vrai, mis à feu et à sang l'Université en annonçant la visite» de son ami espagnol que ce dernier a craint de voir ces excès de faveurs renouvelés, se doutant d'ailleurs que du brasier allumé l'hiver antérieur il restera "des étincelles". (89) De Porto il s'écriera, commentant les honneurs qui l'ont accablé à Coïmbre:

"Yo que por la misericordia de Dios me reconozco decia entre mî unde hoc mihi? Un sor canonigo de Santa Cruz ya me significó que tenia encargo de V. E. para cumplimentarme, y otros muchos me dixeron que me esperaron en vano el passado $\mathrm{Hi}$ bierno, este es el aquae lente caput sacraem.(90)

Par delà l'étonnante image du réseau de relations entretenu par Cenáculo dans le Portugal tout entier, avec ce que cela suppose d'organisation postale, par delà la vision confortée qui nous est donnée d'un maintien de l'emprise pombaline sur les élites du pays, s'ébauche un tableau de la vie en société de l'époque: on se réunit pour causer, autour d'une collation qui met les esprits en verve, à l'écoute d'une musique qui prédispose aux envolées. Bayer à Evora, au cours d'une soirée chez le notable Maldonado, rencontre un médecin érudit, "versé en histoire littéraire", qui joue "divinement" de la viole:

"Yo en mi vida he visto cosa no solo igual, pero ni que se le parezca. A mi me admiró, y me tuvo encantado todo el rato que tocó. Para mostrar su destreza, y quan dueño estaba hecho del diapason de su vihuela, la presentaba á qualquiera de los circunstantes y le decia: pise Vm. con el dedo la cuerda que quiera y el traste que quiera. Haciase assi, y por el sonido que la cuerda hacia, tocaba después por aquel termino un quarto o más de hora, fabricandose un tema ó intención en un momento, la qual seguia hasta el fin con mil glosas y diferencias, con una agilidad increible en ambas manos" (Di., 136).

C'est à cette occasion également qu'il évoque les femmes, presque absentes de son journal. Là comme plus tard à Lisbonne chez le comte de Fernán Núñez, alors ambassadeur d'Espagne, elles sont avant tout curieuses de la reine, qui est portugaise, et de la vie à la Cour. II arrive 
qu'elles offrent un divertissement dansé, ainsi les trois nièces de Cenáculo présentent un petit ballet lors d'un goûter donné chez elles, dans la capitale, en honneur de Bayer (id., 147). Celui-ci a été frappé de la présence au foyer d'esclaves noires, qui ont dû éveiller son intérêt; il les appelle affectueusement dans ses lettres las Morenas et s'enquiert régulièrement de leur sort.(91) C'est l'occasion pour Cenáculo de lui dire qu'il a lui-même acheté un esclave afin de lui rendre sa liberté, une attitude qui ne surprend pas chez l'évêque de Beja, mais dont on ne semble pas avoir d'autres exemples en ce qui le concerne:(92)

"As Morenas de António Duarte, algum fato bom as espera. Comprei agora hum, precizamente para the dar a liberdade».(93)

De retour en Espagne, Bayer restera en communication avec son hôte de Beja, de façon épisodique mais chaleureuse, et l'on est frappé de la liberté de ton, du naturel, de la franchise de ces échanges. Le Valencien, par exemple, n'hésitera pas à demander à son ami portugais une Bible espagnole, de Cassiodoro Reina, dont il croit se rappeler avoir vu deux exemplaires dans la bibliothèque du prélat. II se permet cette requête dans la mesure oủ il fait parvenir à Cenáculo des ouvrages de récente parution en Espagne, dont le Salluste de l'Infant D. Gabriel, et ajoute plaisamment:

"No son todo dadivas. Tienen mis regalos su interés. En la Libreria de V. Exa vî duplicada una Biblia Española, de Cassiodoro Reina, de que yo carezco. El un exemplar está entero; al otro le falta la Portada. Si este no hiciesse aî falta, ó no le tuviesse V. Ex ${ }^{a}$ destinado, se lo pido á V. Ex ${ }^{a}$ con la misma franqueza y satisfaccion con que daré a V. Ex ${ }^{a}$ qualquiera Libro de mi Libreria. Soi Francisco en dar y pedir».(94)

Cenáculo, bien entendu, lui envoie l'ouvrage désiré, mais il tarde quelque peu, car il lui fait tenir un exemplaire irréprochable, dont il a par conséquent passé commande aux nombreux libraires qui s'occupent de ses achats. (95)

Tout porte donc à croire que Bayer apprécia lors de son séjour au Portugal la délicatesse et la générosité dont l'entourèrent Cenáculo et les siens, et qu'un réel sentiment de sympathie, dépassant la simple réciprocité de goûts, d'aptitudes ou d'intérêts, naquit en lui. Ne dit-il pas, évoquant son séjour à Lisbonne chez la soeur de l'évêque de Beja, qu'il s'y sentait comme chez lui:

«aquella Casa, donde recibî tantos favores que no sabrê ni podrê bien ponderar; y yo no sê con quê motivo, ni a quê titulo, quando estaba en ella y en su buena compañia, me figuraba dentro de mî que estaba en mi casa y con los mios, y estaba en la misma libertad que tuviera con mis Hermanos y Parientes».(96) 
II ira -c'était la coutume à l'époque- jusqu'à composer une poésie latine en hommage à Cenáculo, "en traversant la Serra da Estrela», poésie dont il enverra aussi un exemplaire à l'un des savants rencontrés à Coïmbre, António Ribeiro dos Santos, futur Directeur de la Bibliothèque Royale de Lisbonne. (97)

Quelque jalousie secrète se glissa-t-elle entre les deux hommes? On est parfois tenté de le penser, par exemple lorsque Cenáculo se montre un peu dépité de la trouvaille et de l'achat par Bayer chez un libraire lisboète d'un Geografo Nubiense, une impression médicéenne de Rome, 1592. (98) On a la preuve de son léger agacement par un passage d'une lettre de Salgado à son évêque:

"O Geographo Nubiense que levou Bayer não nos servia. He todo em arabigo, e não serve senão aos professores (...). Farei diligencia se se descobren.(99)

Usant peut-être d'un stratagème de retour, Cenáculo écrit alors à Bayer qu'il croit bien se rappeler que celui-ci a deux exemplaires de l'ouvrage dans sa bibliothèque et lui demande l'un d'entre eux:

"Diz V. Sa Illma que he franciscano em dar e pedir. Ancor'io son pittore. Vou rogarlhe, se a memoria não falta, que tendo $\mathrm{V} . \mathrm{S}^{\mathrm{a}}$ Illma na sua livraria duplicado o Geografo Nubiense, me obrigue com hum exemplar. Se for o arabigo, aqui há quem o traduza». (100)

Bayer fera toutes les recherches nécessaires, commandant, dit-il, le Nubien à Paris, à Rome, à Florence, sans succès. Cenáculo tentera de l'obtenir auprès des Mohedanos, il en parlera à Muñoz, qui lui confirmera l'existence de deux exemplaires dans la librairie de Bayer...(101) L'affaire en resta apparemment là, et l'on peut donc dire que c'est à la barbe de Cenáculo que l'orientaliste valencien a ravi à Lisbonne un ouvrage rare. L'évêque de Beja eût donc pu aisément se le procurer s'il avait eu Bayer pour limier. Celui-ci est très admirè en effet pour son flair, et Salgado s'en montre même discrètement irrité: "Je ne savais pas", dit-il par exemple, "qu'il y avait à Lisbonne autant de stèles que Bayer en a découvert" (102). Quant aux livres:

"De livros arabes se prové; e o demais he que andou V. E. tantos annos para descobrir as Biblias castelhanas, e não menos de sinco ja tem comprado em Boreln.(103)

Mais en fait l'épisode du Nubien souligne encore le rapport d'identité qui lie à n'en pas douter Bayer et Cenáculo, et place sous un éclairage intéressant leurs rôles respectifs dans leur pays. Il est clair en effet qu'une forte personnalité comme celle de Cenáculo, dans un Portugal aux dimensions réduites, arrive à dominer une époque, et dans son cas précis, 
malgré les vicissitudes politiques du "Revirement" de 1777. Comme depuis le Couvent du Jésus à Lisbonne, il rayonne depuis Beja sur son ordre, sur l'élite nationale, sur la reine même, et continue de happer dans son réseau d'affinités les personnalités européennes d'envergure.

Bayer a certainement été frappé de cette dimension, y a peut-être même vu un exemple, a en tout cas senti le besoin de se placer sur un même plan. On s'explique ainsi qu'il prenne plaisir à dètailler par le menu à Cenáculo les avantages financiers dont il jouit depuis qu'il est bibliothécaire royal. L'évêque de Beja était un homme riche, avec un revenu annuel, tous prélèvements considérés, de 8 à 9.000 .000 de réis par an, et plus, et le Valencien une fois encore ne veut pas être en reste. (104)

A-t-il été impressionné par l'action apostolique de Cenáculo? II le tient au courant de sa propre activité charitable, lui faisant savoir qu'il dispose d'une partie de ses revenus en faveur de diverses oeuvres pies:

"estudio ser pobre, y voi ahora tomando la practica de esta notabilissima Facultad. Sin lo de mi nueva Parroquia cuia fabrica y dotacion me cuesta al pie de treinta mil pesos fuertes y mas: voi a dar otros diez mil á una Casa de Enseñanza de Jovenes Educandas, y á una Carzel de miserables presas por sus desemvolturas". (105)

Il avait sans doute eu l'occasion d'apprécier la largesse des aumônes de Cenáculo qui d'ailleurs songeait, lui aussi, à ouvrir une Maison d'Education pour jeunes filles. (106)

S'il y eut légère rivalité, elle se plaça en tout cas très haut, en une sorte d'émulation où l'amour de la vraie science aiguillonnait les intéressés. Lorsque Bayer évoque auprès de son correspondant le contenu de sa bibliothèque personnelle, qu'il donne à l'Université de Valence, ce n'est pas pour le piquer ou l'éblouir, c'est parce qu'il sait avoir affaire à un fin connaisseur qui appréciera a leur juste valeur les Collections de Bibles ou de Conciles, les oeuvres de Muratori, de Bossuet et d'autres, les tomes du Journal des Savants et les traités d'Histoire Naturelle dont il a patiemment constitué sa librairie. II conclut d'ailleurs ainsi:

"Veo con gusto mis Estantes medio vacios, porque hago juicio que mis libros se manejaràn en Valencia con mas utilidad y fruto que los hè manejado Yo, especialmente por los pobres que no pudieran comprarios; y de camino me curo, como dicen en salud, esto es me quito de sobre mî el grande dolor que en una enfermedad me causaria el pensamiento de el hado de mis libros"..(107)

Ces livres, lui répond Cenáculo, portent la bonne parole, ils sont une base compacte, solide. Ils ont du prix, ils sont utiles, et nécessaires. Mais ce qu'il y a de plus rare, c'est ce que l'on a dans l'âme, qui donne un coeur 
constant, après que l'on se retrouve devant les rayonnages vides. "Les richesses", ajoute-t-il, "que vous possédez sur l'Orient, les raretés dont vous êtes le dépositaire, ne disparaîtrons que dans l'éternité". (108) Et il l'encourage dans sa tâche de bibliothécaire royal, regrettant de n'avoir pu continuer lui-même dans cette voie, comme lorsqu'il était président de la Real Mesa Censória:

"se o meo trabalho de ajuntar curiozidades literarias - passa de sincoenta annos - merecerá por minha parte o infaustibus avibus do seo admiravel paisano o $\mathrm{Sr}$ Deão Marti? Vossas intençoes me confundem no pensamento que V. S. IIIma me escreve de el hado de mis libros para os ver depositados em sua vida nas dignas mãos da sua patrian.(109)

Cet échange de haute tenue avec Bayer a probablement joué un rôle dans la décision prise plus tard par Cenáculo de léguer ses livres à Evora d'une part, à la Bibliothèque Royale de Lisbonne d'autre part.(110)

Ainsi la rencontre, unique, entre Manuel do Cenáculo et Francisco Pérez Bayer, permet un dialogue fécond, poursuivi jusqu'à la mort du Valencien. De la même façon, l'accueil fait à Cenáculo par Mayáns en 1768 á Valence a suffi, sans que jamais les deux hommes ne se revoient, à alimenter vingt ans de correspondance assidue. Rafael Mohedano no rendra visite, lui aussi, qu'une fois à l'évêque de Beja.

On se prend à rêver devant l'importance de la lettre à cette époque, qui perpétue la mémoire en défiant le temps, rendant les interlocuteurs aussi vivants que si l'on continuait de les voir, tels qu'en eux-mêmes l'éternité vous en laisse le souvenir.

Lorsque Cenáculo apprend la mort de Mayáns, la première chose qu'il demande d'ailleurs à Juan Antonio est un portrait du défunt, qui seul pourra désormais lutter contre l'oubli.(111) || souhaitait également en garder un de Bayer et demande à Paulo Clemente, un portraitiste de Lisbonne, de s'en charger. La modestie du Valencien empêchera la bonne suite de cette affaire, d'après Salgado:

"Elle não era possivel consentir. Não se podia apanhar a boca e nariz, e posto que o sogeito fez todas as boas deligencias, nada se pode concluir e effectuar, e ficámos com a simples lembrança e com o sentimento de não podermos dezempenharn.(112)

Mais la correspondance poursuivie avec Cenáculo rendra présents l'un à l'autre les deux interlocuteurs pendant dix ans.(113) Muñoz est attendu avec impatience à Beja après que Bayer l'a recommandé. (114) De même le diplomate et savant bibliographe Joaquim Ferreira Gordo sera reçu avec tous les égards par le bibliothécaire de Carlos III, auquel il se présente muni d'une lettre de recommandation de Cenáculo. (115) 
Le deuxième temps fort du voyage de Francisco Pérez Bayer est la découverte qu'il fait de Lisbonne, cette Lisbonne qui porte à jamais la griffe de Pombal, et qu'il appréhende comme un tout, ému par sa beauté naturelle, confondu par son architecture urbanistique, intéressé par son histoire, curieux de son commerce. Le passage du Tage, qui dure deux majestueuses heures, exalte son esprit:

"daba gusto el hirse insensiblemente acercando a este gran pueblo (Lisbonne) en hora en que el Sol lo batia de lleno y en un dia claro como aquel era" (Di., 141).

II est tout de suite fasciné par le spectacle du port, "fort agréable à la vuen (ibid.), et il éprouvera du plaisir à s'y promener de temps à autre en fin de journée (id., 145, 152), avouant qu'il est surpris par sa capacité (id., 142).

L'occasion lui sera donnée d'admirer le site de la ville, lors d'un déjeuner à l'Ambassade d'Espagne, installée sur une hauteur. II monte sur la terrasse et découvre toute la perspective jusqu'à Belém, charmé par la diversité qui s'offre à lui, "fleuve, mer, forêt de bateaux et barques, maison, palais, jardins, collines, résidences sur l'autre rive et dans la villèn: puedo asegurar no haver visto jamás espectáculo más agradable y vario (id., 151. 152).

D'autre part, la conception même de Lisbonne le frappe d'emblée et lui semble d'une indéniable nouveauté:

"Según ibamos, observaba yo el rumbo de muchos edificios, su igualdad y la del material de que constan, su fortaleza, y hermosura, lo espacioso, largo y derecho de las calles, y me parecia no haver asta ahora visto su semejante» (id., 141).

La Place du Commerce, bordée "par la mer, ou le fleuve, car là c'est tout un", l'enchante, et il y revient au lendemain de son arrivée, afin de la mieux considérer, concluant qu'aucune de celles qu'il a pu voir au cours de son existence, pas plus celle de Saint-Marc à Venise que la Piazza Navona à Rome, "ne lui sont comparables en grandeur et beauté". Lorsqu'elle sera complètement terminée, ajoute-t-il, "ce sera l'une des grandes et belles réalisations européennes" (id., 142). Quant à la statue de D. José I, elle est "incomparablement plus grande que celle de Felipe IV au Retiro, que celle de Louis XIV à Montpellier" et que toutes celles qu'il a vues en bronze jusque là:

"Dicen que no solo la estatua y el cavallo sino las figuras, trofeos, y adornos, que forman el grupo sobre que pisa el caballo, és una sola pieza vaciada y diseñada y hecha en su modelo por artifices portugueses (...) La base sobre que está eregida és de bellos marmoles, y el todo excede en altura á los edificios de los tres ramos ó brazos que forman la plaza. En suma Regis Opus" (id., 143). 
Un monument, dit-il encore, "qui fait indubitablement honneur au pays».(116)

En sa qualité de prêtre, il consacre une bonne partie de son temps à la visite des églises, nous en laissant des témoignages d'intérêt, tant au sujet de leur architecture qu'à celui des cérémonies qui s'y déroulent. C'est ainsi qu'à São Bento, qu'il trouve "magnifique»,(117) il assiste à une messe solennelle en l'honneur de Sainte Gertrude, dont il apprécie l'excellente musique. Il est plus réservé sur le sermon de l'orateur, dont il n'a d'ailleurs pas tout compris -c'est la seule allusion à une difficulté d'échange au plan linguistique, mais elle paraît due à l'obscurité ampoulée du propos:

«aunque no acababa bien de entender, hize juicio de que hechaba el Orador... Ampullas etc. sesquipedalia verba" (Di., 146).

A São Roque -l'ex-maison des Jésuites, il le signale au passage-, (118) il est enthousiasmé par un Office des Morts célébré par la Confrérie des Musiciens de Lisbonne. II a pourtant assisté à Bologne le jour de la Saint Pétronius à une messe chantée réunissant un beaucoup plus grand nombre de voix, mais elle n'a jamais égalé l'harmonie et la beauté de celles qu'il lui est donné d'entendre ce jeudi 28 novembre au Portugal:

"Cantaron a la verdad divinamente, y yo me huviera estado alli como estaba, esto és de pié y sin comer, i mui gustoso todo el dia" (Di., 162).

II n'a pu trouver place assise, étant arrivé après les ambassadeurs et n'ayant par conséquent plus osé s'avancer. L'église tout entière a été disposée pour l'orchestre et le choeur, qui compte au moins dix castrats. (119) La musique est de Jommelli:(120)

"Estaba el tablado para ella (la musique) dispuesto en el testero de la Iglesia con dos brazos que corrian uno por cada lado de la nave y en cada brazo havia tres gradas. En el testero estaba el Maestro de Capilla y las voces: En los lados los instrumentos (...) A cada lado havia tres contrabaxos, y tres violines ó violoncelos, que estaban en la grada inferior: sobre ellos en las otras gradas havria a cada lado bien doze ó mas violines que a la verdad parece que sacaban á la Iglesia de su quicio» (Di., 161).

Bayer a aussi le loisir d'apprécier des églises en construction, comme celle du Sacré Coeur de Jésus où "tout, dit-il, est somptueux et achevé dans le moindre détail',(121) De l'église de Saint-Antoine, il estime l'edifice "beau et spacieux", ne pouvant en dire plus car seule la nef est achevée et il n'y a pas encore de transep.(122) Quant à la Sé Velha, restaurée depuis les dégâts que lui avait causés le tremblement de terre, elle lui paraît «vaste et belle». On en a conservé tout ce qui était possible.(123) 
Une seule église lui déplaît, qu'il trouve de fort mauvais goût: la Patriarcale, soit São Vicente de Fora, pourtant construite sous Felipe II sur des plans de Filippo Terzi supervisés par Juan de Herrera. "Les statues des saints qui occupent les niches sont ridicules", ajoute-t-il, "c'est du moins mon point de vue». A l'intérieur, elle est vaste, riche dans le goût moderne, en forme de croix latine.(124) Le quartier où elle est située est difficile d'accès et la seule critique élevée par Bayer contre Lisbonne est formulée à son propos:

"(la Patriarcale) está media legua de la posada, mucha cuesta, muchos lodos, y unas calles que yo no hallo con quienes compararlas ni en Toledo, ni en Sevilla, ni con las que llaman en Granada faltriqueras y tan puercas y lobregas que no sé como hái quien se determine á morar alli” (Di., 155).

Les remarques du voyageur prennent aujourd'hui toute leur importance pour qui s'intéresse à l'urbanisation de Lisbonne, à la datation précise des travaux entrepris. II est significatif que s'ordonnent sur un double plan ses visites monumentales: à l'ombre de la statue équestre, les chantiers en activité sont protégés par la souveraine, et l'architecte qui en est responsable, Mateus Vicente, est celui de Queluz, ce foyer de la réaction antipombaline.

Le souci d'objectivité de Bayer est, par ailleurs, extraordinaire et mérite qu'on lui rende hommage; aucune mesquinerie, aucun esquivement, jamais il ne donne l'impression d'une quelconque tendance a sous-estimer une réalité portugaise qui le séduit et souvent le laisse pantois. De la part d'un Espagnol, c'est une honnêteté qui ne va pas forcément de soi et prouve un jugement impartial, digne d'un esprit éclairé comme celui de l'éminent érudit qu'est Bayer.

Un autre pôle de ses activités lisboètes est à mettre en relation précisément avec les missions de l'académicien, du savant, du bibliophile.

Ce sont d'abord ses promenades archéologiques, qui le conduisent par exemple dans la rue Sainte Madeleine, où il examine des inscriptions retrouvées lors d'excavations. (125) Une autre fois, il recopie une seule inscription, comme celle qui est encastrée dans le mur d'un magasin, ou celle qu'il aperçoit dans l'enceinte du Couvent de San Caetano.(126) II en reconnaît aussi un certain nombre du côté des anciennes douanes, ainsi qu'au Couvent du Jésus, "un des plus magnifiques de la ville».(127) En ce dernier endroit, elles sont exposées sur une petite terrasse ornée de pots de fleurs:

"Todas estas son piedras pequeñas facilmente transportables de un sitio a otro; pero me aseguraron el P. General y los demás que nos acompañaban que todas se hallaron en Lisboa y en las zanjas que se abrieron para el edificio de aquel Convento" $(D i ., 158)$. 
Cette dernière visite semble avoir donné lieu à un malentendu, si l'on en croit Salgado, qui écrit à l'ancien Supérieur du Jésus qu'est son évêque:

"Levei Bayer no convento logo nos principios de sua estadia nesta corte, sendo ajustada a sua hida e dando se por escrito hora certa. Entramos ás 9 e até ás dez e meia não apareceu ninguem. Sintio se muito Bayer e the roguei não fallassemos nisto, nem huma palavra". (128)

Salgado, sur les instances probablement de Cenáculo, désirait faire visiter au voyageur le musée du confesseur du prince consort, le P. José Mayne, installé au Jésus. Les démarches postérieures au rendez-vous manqué - dû à quelque opposition à laquelle il est fait une allusion voilée - finissent par aboutir et Bayer verra les collections du confesseur en fin de séjour:

"Comenzamos por el museo de medallas, cosa pobrissima (...) Tambien lo de Historia Natural está mui á los principios. Pinturas si tiene algunas que me parecieron buenas. Libros algo moderno. Poco más" (Di., 157).

Quelle décadence, en somme, depuis le départ de Cenáculo à Beja!

En revanche, il y a beaucoup d'inscriptions anciennes. Outre les petites, au nombre de sept, il y en a onze grandes, qu'il serait difficile de transporter; plusieurs ont été laissées par l'évêque de Beja. Au total, Bayer n'en recopie donc pas moins de dix-huit.

II visite un autre musée, également privé, celui du marquis d'Angeja, successeur de Pombal. Si le médaillier ne l'impressionne guère, il ne cache pas son admiration pour le département d'Histoire Naturelle, appréciant les minéraux - quartiers d'or et d'argent de taille exceptionnelle, pierres précieuses et roches diverses-, les végétaux pétrifiés, les èchantillons d'Ornithologie et d'Ichtyologie, les armes et instruments trouvés lors des conquêtes":

"Armas de $10: 3$ !ndios de madera. Instrumentos para cortar árboles y labrar los utensilios de las casas, sillas, mesas, arcas, telas larguissimas y de séis y siete palmos de ancho á manera de los papeles gruesos de la China, sin que se reconozca texido, ni urdimbre ni trama mui sutil y tan flexibie como las muselinas lo que á mi me causava admiracion» (id.,153).

Une momie égyptienne très bien conservée retient son attention, ainsi que des pièces de vaisselle de cuivre, et des porcelaines chinoises.

La librairie, elle aussi, l'intéresse bien entendu:

"és libreria no grande pero selecta en punto de historias, nobibliarios, legislación, fueros y costumbres de Portugal” (id., 154). 
et il apprécie également les tableaux, peu nombreux, mais choisis. Quel dommage que l'ensemble des richesses exposées dans ce musée y soient à l'étroit, conclut-il. (129)

Le P. José Mayne, député ordinaire à la Real Mesa Censória depuis 1773, est considéré comme l'un de ces éléments du clergé qui surent tirer parti du "Revirement": nommé aumónier royal en lieu et place de Cenácu10, confesseur du mari de la souveraine, on doit considérer qu'il abandonna la cause de Pombal non sans habileté puisqu'il continua de frayer avec ceux qui lui restèrent fidèles, comme l'évêque de Beja précisément. De la même façon, le marquis d'Angeja, D. Pedro José de Noronha Camões de Albuquerque Moniz e Sousa, troisième du nom, fut l'un des ennemis jurés du favori de José I, mais avec suffisamment de dissimulation pour que ce dernier ne s'en aperçût pas. La reine ne s'y trompa nullement, couvrant Angeja d'honneurs à la chute de Pombal, le plaçant à la tête du Trésor Public, le nommant chef des armées et enfin premier ministre. Angeja était considéré comme l'anti-Pombal par l'opinion publique qui usait du dicton: mal por mal, antes Pombal.

Sur ces deux exemples, on saisit assez bien avec quelle réalité du Portugal Bayer est confronté à Lisbonne: c'est à n'en pas douter celle de la succession, mais sur un mode discret, car de l'ancien régime il reste de puissants éléments comme Cenáculo par exemple, dont on comprend qu'il tient encore bien des ficelles, mais sans être désormais le deus ex machi. na qui avait accueilli et piloté Rafael Mohedano en 1773. L'aristocratie muselée pendant vingt ans prend revanche en s'affirmant elle aussi comme élite culturelle et scientifique, s'appuyant sur les membres du clergé qui cherchent à se promouvoir. On s'explique alors l'état d'abandon dans lequel Bayer trouve la bibliothèque de la Real Mesa Censória, dont Cenáculo s'occupait avec un soin jaloux, et qui est devenue un vaste capharnaüm, où s'entassent beaucoup de livres en vrac (Di., 151). Bayer s'en souviendra lorsqu'il se retrouvera à la tête de la Bibliothèque Royale peu de temps après, écrivant à l'évêque de Beja:

"Estuvo esta B. R. años al cuidado ó descuido de cierto varon de nuestros Togados (...) (130) que no habia nacido para Bibliotecario, ni creo que jamas hizo una idea cabal de su oficio (...) $\mathrm{Ha}$ llê un cumulo de cerca de ciento y veinte mil volumenes, no tan malo a la verdad, como lo de la Mesa Censoria de Lisboa (ha. blo por la falta de orden), pero no tan reglado como convenía, y debieran. (131)

Le tribunal en question n'était-il pas l'un des plus beaux fleurons du système mis en place par le ministre déchu pour canaliser la culture selon ses critères?

Vue sous cet angle, la sollicitude de Cenáculo à l'égard de Bayer signifie aussi une sorte de démonstration d'un pouvoir encore présent, fort, 
ramifié, tel qu'on s'accorde aujourd'hui à apprécier l'après-pombalisme, qui continue par des menées souterraines à faire régner les idées de la grande figure politique et idéologique du Marquis.

Le Valencien reste discret sur cet aspect des choses, qu'il n'est pas toutefois sans pressentir. S'il dit dans son journal avoir reçu la visite d'António Pereira de Figueiredo, député de la Real Mesa et l'un des piliers du pombalisme, et en avoir reçu un ouvrage intitulé Biblioteca Monasteri A/. cobatiensis (Di., 146), il pase sous silence un cadeau autrement compromettant de l'oratorien: deux titres en hommage au régime antérieur, ParaIlelo de Augusto Cesar, e de D. José o Magnanimo, Rei de Portugal, et Statua Vocalis, sans doute relatif à la statue équestre.

V. Salgado, qui nous renseigne à ce sujet, (132) ajoute qu'il faudra faire parvenir à l'érudit la collection des oeuvres "sur les choses de la Cour", que Pereira a imprimée sur ordre de Cenáculo. (133)

On peut penser que Bayer préférait la circonspection, non seulement en tant qu'étranger — l'immunité dont il jouit ayant pour revers, en quelque sorte, une certaine neutralité-, mais aussi parce que les temps ont changé et qu'avec le recul on condamne les excès. C'est ainsi qu'il laisse passer une claire réprobation à l'égard des procès suivis d'exécutions capitales intentés par Pombal aux nobles impliqués dans l'attentat contre José l, qui avaient eu un grand retentissement en Espagne:

"Vimos tambien el solar de las casas que fueron del Duque de Aveiro, y se arrasaron, y el Padron que en ellas se erigió por memoria en los siglos venideros. Tambien vi aunque á alguna distancia el lugar donde se executó la sentencia de los reos. Solo el recordarlo á vista de los sitios me causaba horror" (Di., 154).

A Beja, il avait recopié une épigramme satirique à propos de Clément XIV et de la dissolution de la Compagnie de Jésus, non sans estimer:

"No dexé de admirar la libertad del Poeta, y que tan sin disfraz se hablase de un assumto tan delicado, y problematico. Ni me atrevi a preguntar cuyo era. Ello vale mui poco, y no tiene alma ni calor, ni estro, ni propiedad" (id., 127).

Salgado n'ose pas à son tour recopier le commentaire de Bayer, voulant éviter une marque de défiance... (134) Mais on sonde le visiteur en lui montrant un livre intitulé Defensa do Coração de Jesus, "par un Jésuite": methodo escolastico de que rio bastante, conclut Salgado, (135) qui donne parfois dans ses lettres à son évêque l'impression de se servir de Bayer comme d'un brûlot en terre ennemie, se réjouissant que chez le marquis d'Angeja il évoque les collections de monnaies de Cenáculo à l'avantage de ces dernières, ou fasse "un grand éloge" de l'évêque de Beja chez Aires de Sá e Melo, ancien ambassadeur de Portugal á Madrid. (136) 
Le voyageur perçut-il les échos de ces luttes d'influence encore vives cinq ans après la disgrâce du favori? Son journal laisse essentiellement passer une appréciation objective de la réalité de la capitale. Ville historique, ville monumentale, ville de culture, Lisbonne a de quoi contenter un humaniste distingué comme le Valencien, qui va y trouver une autre source de satisfaction intellectuelle en donnant libre cours à l'une de ses passions: la recherche de livres anciens. C'est en effet un infatigable fouineur. "Enveloppé dans (sa) cape", par tous les temps, il va de libraire en libraire et scrute leurs fonds. II y a cinq grandes librairies, (137) dit-il, quatre françaises, Veuve Bertrand, Borel, Paul Martin, M. le Beux, et une italienne, Reicend - un turinois - (138). En outre, trois ou quatre librairies d'importance appartiennent à des Portugais. Chez ces différents marchands, il procède à des acquisitions qui correspondent à ses goûts et à sa formation, en plus de la valeur intrinsèque des ouvrages. II écrit à Cenáculo de Madrid le 9 janvier 1783:

"En Lisboa comprê algunos libritos: tres Biblias Españolas: un Testamento nuevo español: el Geografo Nubiense: varias Biblias Hebraicas con comentarios Rabbinicos: la colecion casi entera de Libros de Cavalleria: mucho Arabigo, y algo de Historia de España y de Humanidad".

Les "petits livres" en question sont au total, selon mes calculs, plus de cinquante dont la moitié de manuscrits, de quoi remplir quatre caisses (Di., 155). On trouve divers titres relatifs á l'Historia del regno Balearico; (140) des traductions en castillan de textes sacrés; des ouvrages religieux; des chroniques, celle d'Alfonso el Sabio et celle de D. Sancho el Bueno y $D$. Fernando el emplazado; (141) un grand nombre d'oeuvres "orientales" en grec, en arabe, en hébreu. L'une des trouvailles de Bayer, qui semble l'intéresser au plus haut point, est un Regimiento de la vida Humana, ó Espejo de Sabios con el tratado de los sueños y su interpretacion, d'Almosnino, (142) écrit en caractères rabbiniques, mais sur les mots espagnols, et il en transcrit de longs fragments dans son journal. 11 y a, bien entendu, de nombreux titres en latin, dont certains se rapportent à des textes grecs, comme les Poetae Graeci Veteres qui heroico et Lyrico carmine scripsere. Quant aux romans de chevalerie, pour lesquels il devait avoir un penchant, il explique ainsi leur achat:

"importa que se conserven estos libros para que se vea el modo de pensar de nuestros antiguos y el gusto del vulgo de España aun en el siglo XVI en que florecieron en ella tantos sabios. Convienen especialmente estos libros en una libreria publica, y yo holgaria mucho con tener los que faltan para completar la colección" (Di., 145).

Il signale "un chevalier errant dont (ii) n'a jamais entendu parler": Policisne de Beocia, Valladolid, $1602{ }^{(143) . ~ D ' a u t r e s ~ s u r p r i s e s ~ l u i ~ s o n t ~ r e ́ s e r v e ́ e s, ~}$ 
ainsi n'avait-il jamais vu une impression madrilène de $1670,4 .^{\circ}$, de la Vida de Santo Tomás de Villanueva, par Salón,(144) ni un Testamento nuevo en Español antiguo, Venise, $4 .^{\circ}, 1556$, dont la version est très différente de celle d'Encina, et qui est un ouvrage "rarissime». Borel, qui le lui vend, n'en a jamais vu qu'un autre exemplaire, et il est, comme les autres libraires avec lesquels Bayer traite, loin d'être un vulgaire vendeur de livres. On remarque en effet que le dialogue engagé par le Valencien dans les librairies lisboètes se situe entre connaisseurs, ainsi à propos de deux romans de chevalerie:

"Escaparonseme Palmerin de Oliva, y Don Girongilio de Tracia,(145) los quales tuvo tambien este mismo librero (Veuve Bertrand), y el primero me dixo que lo havia vendido: el segundo me dió esperanzas de que lo hallaria y me lo venderia» (Di., 145).

Et Bayer n'en est que plus content de s'être procuré à bas prix son ouvrage rabbinique sur mots espagnols, précisément chez ce même Borel:

"El libro és raro, y mucho, y el mercader, que no sabia de él sino el titulo, quando yo le expliqué lo que contenia, y que estaba escrito en español sintió no haverlo sabido antes para vendermelo mas caron (id., 150).

II profite de ces contacts pour mettre sur pied de futurs rapports commerciaux avec la librairie portugaise, comme nous l'apprend Salgado. "Bayer", dit-il à Cenáculo dans une lettre du 22 avril 1783, "a écrit aux marchands de livres et leur a fait tenir par Carreño ses oeuvres en abondance; elles sont vendues 5.600 et chez Bertrand à 6.400".(146)

Le livre est en effet, avec la lettre dont je soulignais plus haut qu'elle permettait aux absents de se maintenir dans le souvenir de leurs correspondants, le grand passeport de l'échange intellectuel entre deux pays. Rentré à Madrid, Bayer envoie à Cenáculo, par l'intermédiaire du secrétaire d'Ambassade du comte de Fernán Núñez, D. Joseph Antonio Villaamil, un exemplaire du Salustio de l'Infant Gabriel, qui a déjà une certaine notoriété au Portugal -le marquis d'Angeja l'a vu, les moines de Mafra en ont entendu parler-, et trois exemplaires de son dernier écrit, De Nummis HebraeoSamaritanis, un pour l'évêque de Beja encore, un autre pour Vicente Salgado et le troisième pour Pereira de Figueiredo. L'érudit complète son envoi à Villaamil de quelques titres:

"Vá tambien en papel algo maltratado (porque no se há hallado mejor) mi Damasus de Laurentius etc. y un exemplar de la traduccion española del Catecismo de San Pio quinto que acaba de imprimirse en Valencia. He puesto assimismo un juego de las estampas del Salustio y otro de las de mi Disserton De nummis etc. Val ultimamente dos estampas de algun merito que se 
hàn gravado recientemente aqui, y veré si puedo adquirir otras y las incorporarên. (147)

L'allusion aux gravures marque l'intérêt que l'on porte à la représentation visuelle, elle aussi garante de pérennité. Bayer à Lisbonne cherche vainement à acquérir un dessin de la statue équestre. Il en avait vu deux avant de se rendre au Portugal, l'un au burin très fin et très délicat, mais avec peu d'arrière-plan, l'autre au fusain "exécuté divinement à Londres", mais il n'a pu les trouver à Lisbonne (Di., 143).

Par la suite, l'échange de livres se poursuivra, et Bayer proposera à son correspondant la Biblioteca Arabiga de Cassiri, la Biblioteca Griega Matritense d'Iriarte, la Polygraphia de Rodríguez, le tenant au courant de l'actualité littéraire valencienne, et nationale.(148) Sur ce dernier chapitre, il envoie une brochure publiée à Paris et qui s'inscrit dans la querelle des apologies de l'Espagne, sans cacher le moins du monde son point de vue:

«es propiamente un puntalillo que se pone á nuestra (nuestra digo, esto es comun á toda la Peninsula) Literatura ruinosa. Tengo estas apologias por inutiles. Si es cierto que en España siglo y medio há ó mui cerca esto es desde por los años 1640 que somos bolonios? Si se saben las causas, el principio, el aumento, progressos y estado de nuestra bolonieria: a qué gastar tiempo y papel en estas defensas? Mejor es confessar de plano nuestra desgracia, y cada uno por nuestra parte emendarnosn.(149)

Ce n'est pas la première fois que la rupture de 1640 est évoquée avec regret, comme le signal d'une régression, d'un affaiblissement de la Péninsule dans le concert des nations européennes. Cenáculo laisse percer une nostalgie semblable quand il constate à contre-coeur auprès de $\mathrm{R}$. Mohedano que de l'ancienne union ne subsiste plus qu'une "communication purement spirituellen. (150)

En tout cas, libraires, intermédiaires, membres du corps diplomatique, voyageurs, érudits, une pléiade d'industries concourent à la diffusion des idées entre l'Espagne et le Portugal, et le récit de Bayer en donne une image profuse, vivante, qui illustre, avec la maturité culturelle d'une métropole et de son élite, l'importance des échanges commerciaux mis en jeu.

II restait à Francisco Pérez Bayer un aspect capital de la réalité portugaise de l'époque à appréhender, celui de la politique de formation des esprits. S'il a été impressionné par Cenáculo, si Lisbonne a amplement satisfait sa curiosité intellectuelle et artistique, il est dubitatif quant à une évolution en profondeur dans une perspective éclairée. Reçu par Aires de Sá, il s'exprime de façon pessimiste: 
"Dixele a Su Ex ${ }^{2}$ que en España y Portugal no havia bastante calor en los estomagos para digerir a los sugetos grandes: que reinaba el mismo astro fatal etc.n.(151)

Non pas qu'avant de quitter Lisbonne il n'ait pas eu l'occasion de rencontrer d'éminentes personnalités du monde des savants, de même qu'il avait eu le loisir de parler avec des notables cultivès, tant à Beja qu'à Evora. Mais il s'est agi d'échanges ponctuels, comme les visites de Pereira de Figueiredo et de José Correia da Serra, tous deux amis de Cenáculo, qui les avait avertis de la visite du Valencien. Le premier, déjà évoqué, est une figure d'importance: auteur de l'ouvrage régaliste Tentativa theologica, qui eut un certain retentissement en Espagne,(152) connu pour ses positions gallicanistes et son anti-thomisme, c'est un homme qui réussit, lui aussi, à traverser la tourmente de la disgrâce de Pombal, même s'il eut partie liée avec le favori de José I, connaissant toutefois une sorte de semi-retraite à partir de 1785 au Couvent de l'Oratoire des Necessidades. Le «Fébronius portugais" a laissé une considérable production littéraire et scientifique et entretenait des relations épistolaires suivies avec Mayáns.

Le second, l'abbé Correia da Serra, est l'un des fondateurs et animateurs de l'Académie des Sciences portugaise, créée en 1777 et dirigée par le duc de Lafões. Ce dernier, revenu d'exil après la disgrâce de Pombal, et l'un de ces nobles persécutés par le Marquis, ne fera pas moins de l'institution à laquelle il est placé une société savante digne des ambitions et de l'esprit de son ennemi déchu. Correia da Serra, naturaliste renommé, se lia d'amitié(153) avec Muñoz et les deux hommes restèrent en correspondance. Muñoz, on le sait sans doute, fut membre de l'Académie des Sciences de Lisbonne.

Bayer fera aussi la connaissance du Fr. João de Sousa, orientaliste portugais né à Damas et premier titulaire de la chaire d'arabe créée en 1775 au Couvent du Jésus. Auteur de divers ouvrages sur la langue arabe, chargé de missions diplomatiques au Maroc et à Alger, il sera reçu à Madrid par le bibliothécaire de Carlos III (auquel il remettra une lettre de recommandation de Cenáculo), devenant par la suite ami de Banqueri.(154)

Tous ces contacts, pourrait-on dire, prèparent le sèjour de Bayer à l'Université de Coîmbre. Mais il va d'abord à Mafra, pour clore son premier voyage, admirant au passage l'aqueduc construit sous Jean $\mathrm{V}$, «une oeuvre vraiment romaine, comparable à n'importe laquelle des anciennes canalisations de Rome et d'Italie par sa solidité et la hauteur de ses arcades"..(155) 
Bayer est en effet intéressé par le Collège Royal institué en 1772 sous l'impulsion de Pombal, en complément au Collége Royal de Nobles de Lisbonne. Cet établissement destiné aux fils de famille se veut un modèle pédagogique. On y enseigne le Latin, le Grec et l'Hébreu, mais aussi les langues modernes (le Portugais, le Français, I'Italien et l'Anglais). La Logique, la Métaphisique, l'Ethique, alternent avec la Physique rationnelle et Expérimentale. La rencontre avec l'équipe de profèsseurs prend tout de suite un tour très cordial,(156) qui améne Bayer à montrer son ouvrage sur les monnaies hébréo-samaritaines et le journal de son voyage, ainsi que le Salustio, cependant qu'on lui remet le Plan d'Etudes du Collège. Le lendemain, il est invité à examiner la biliothèque, de quelque cinquante-trois mille volumes, lui dit-on. Les livres sont encore dans un lieu provisoire, car les travaux de la future salle, qu'on lui montre, et qui lui paraît «aussi large et un peu plus longue que celle de l'Escurial", ne sont pas terminés. L'inspection des rayonnages montre clairement les orientations pédagogiques du Collège. Ils portent en effet des indications révélatrices, ainsi de celui qui annonce: Philosophia rancido-barbaro-sophistico-tumultuoso-inutilis, et réunit sous cette rubrique les tenants de l'obscurantisme, preuve, estime Bayer, "qu'au Portugal aussi on exile la mauvaise philosophie qui a régné dans les Universités espagnoles dans ce siècle et celui qui l'a précédé, et que I'on a coutume d'appeler péripatéticienne et aristotélicienne». Plus loin, on lit: Theologia Escolastica garrulo-disceptatrix, et I'Université de Salamanque y est mise au pilori:

"Godoy, Polanco, los Salmanticenses, y otros ocupaban alli su lugar, y yo decia entre mi: si viera esto el Maestro Apodaca de Salamanca! (Es este un Padre Premonstratense, que aun creo que escribe y morirá escribiendo de el Lumen gloriae: de gloria ut corona: de si purus Homo de condigno etc. de si Angeli in primo suae creationis instanti etc.)" (Di., 167).

Bien entendu, l'enseignement dispensé au Collège repose sur des bases diamétralement opposées à celles qui ont abouti à des discussions sur le sexe des anges. Aussi la conversation "littéraire" engagée entre les maîtres et leur visiteur fait-elle passer la matinée "comme un souffle", donnant lieu à un amène duel verbal:

"Vino uno (de los professores) mui apasionado á Horacio, y de quien dixeron que lo havia aprendido de memoria. En efecto hechó sus rhapsodias de este Poeta siempre que se hablava de asumto á que venia bien. Mostréle en más de una ocasión que no me era nuevo quanto me recitaba de él, y quando acababa de recitar la Oda, Epistola, ó Sermon, ó algun pasage de la Arte Poetica lo proseguia yo, que he tenido desde mi joventud, y conservo una afición grande á este Autor" (id., 167). 
On se quitte sur des promesses: Bayer leur enverra son travail De nummis etc., tảchera de leur faire parvenir un Salustio, que les bons pères sont prêts à acheter "à n'importe quel prix". Il leur laisse son nom, au cas où ils auraient une commande quelconque à passer à Madrid ou en Espag. ne (id., 168).

A Coîmbre, dont l'Université réformée par Pombal connaît un indéniable renom en Espagne et dans d'autres pays d'Europe, Bayer lors de son second voyage approfondit et complète sa vision du système pédagogique portugais en vigueur, dont Mafra lui a montré un exemple, et appréhende une politique culturelle en action, si l'on peut dire, et non pas seulement à l,état de projet. Les Statuts de l'Université ont circulé très largement dans les milieux érudits espagnols; ils ont donné lieu à un échange de lettres entre Campomanes et Pombal, ont été lus et commentès avec intérêt par un Mayáns, un Mohedano,(157) toutes indications qui permettent de penser que Bayer les connaissait. En tout cas, il désirait beaucoup rencontrer les professeurs de cette "célèbre Ecole" afin de pouvoir apprécier la méthode pratique d,étude et d,enseignement qui y était utilisée, mis en appétit d'ailleurs par une conversation érudite avec l'évêque du diocèse d'Elvas, qui avait enseigné le Droit à Coîmbre, et dont il avait estimé ule bon goût et la critique éclairée» (Di., 175). On doit penser qu'un enseignement qui appuyait constamment la théorie sur l'expérience, par des exercices pratiqués dans des établissements appropriés et créés à cet effet, et qui érigeait l'histoire et le document historique irréfutable en fondement des autres disciplines, était particulièrement fait pour intéresser Bayer, réformateur des Colegios Mayores en Espagne et partisan convaincu de la modernité à l'encontre des Jésuites. L'Université reste d'ailleurs une préoccupation essentielle de D. Maria I.

Cenáculo a annoncé la visite d'un homme «rare», d'un homme "simple et qui apprécie tout ce qui en vaut la peinen, et demandé qu'on lui montre les incunables les plus anciens, ainsi que le chartrier de l'Université, car "ce sage aime ce qui touche au papyrus et à la littérature».(158) Bayer est donc attendu et se voit l'objet d'un tourbillon d'attentions, au point qu'il n'a même pas le temps d'écrire à Cenáculo, et attend d'être à Porto pour le faire:

"el caso es que aun ahora que tengo todo el tiempo y lugar que quiero me hallo sumamente embarazado, y no sê por donde comenzar y menos sabria como acabar mi narrativa. Diré pues quasi per saturam, mi Amado Exmo. Señor, que no huvo especie de urbanidad, atencion, de honor, y de finezas que no debiesse yo á su gran benignidad".(159)

II précise alors qu'il a assisté à une session académique à la Faculté de Théologie, où on lui a donné la première place, immédiatement après celle du Doyen, au banc des Docteurs. Les harangues ont toutes été pro- 
noncées en son honneur, après que le Pro-Recteur l'a salué en tant qu'Hospes IIlustrissime. Lors de la procession de Sainte Isabelle, poursuit-il, "on m'a placé avec les Docteurs et les Maîtres". N'a-t-il pas d'ailleurs exprimé le voeu d'être fait Docteur d'une institution qui lui a sans aucun doute paru brillante et excellemment constituée? (160)

II a visité, bien entendu, tous les établissements d'enseignement de I'Université: le Cabinet d'Histoire Naturelle, le Laboratoire de Chimie, l'Observatoire, la Bibliothèque, le Jardin Botanique, et en a retiré l'impression la plus favorable:

"sin atomo siquiera de lisonja digo que hè formado de aquella Insigne Madre Academia un concepto ventajosissimo, por su grande numero de Maestros, Professores y Doctores: por su gran doctrina que hè reconocido en quantos tuve el honor de tratar: por la gran formalidad de sus Grados, Exercicios y funciones: por la extension de sus ramos especialmente en las Ciencias Naturales"..(161)

Bayer a, de son côté, conquis ceux qui l'ont rencontré. II a trouvé "qui l'entende, mais non qui le surpasse, car à la vérité il est difficile de trouver un Philologue plus achevén. (162) Rocha Peniz, l'un des Professeurs, et correspondant de Cenáculo, auquel il rend compte du passage de Bayer, verse dans le commentaire enthousiaste:

"Este genio amavel que com hum fundo immenso de riqueza literaria vio muitas cidades e os costumes de muitos homens, me pareceo comparavel a alguna dessas Piramides do Egypto, de que os artistas admiram a fabrica e ellegancia e de que os annos augmentandolhe a magestade respeitam, contra o seo cosstume, a duraçãon, (163)

le comparant ensuite à Pythagore, à Platon, parcourant le monde une fois l'âge venu: Bayer, lui, sacrifie ses veilles et les commodités de l'existence au bénéfice des lettres, malgré les ans.

On l'autorise, vu ses mérites, à assister secrètement à un examen privé, ce qui, dit-il, est «le Saint des Saints" de I'Université.(164) Au Collège franciscain de São Pedro, où Cenáculo a vécu et enseigné dans sa jeunesse et où il est reçu avec des égards particuliers -R. Peniz en serait-il le Supérieur? - il examine diverses médailles, dont plusieurs lui sont inconnues malgré son expérience de cabinets italiens fameux.(165)

Enfin, de crainte que toute cette science ne le lasse un peu, on l'invite à souper, on le comble de douceurs et de présents.(166) II fait la connaissance de nombreux professeurs, parmi lesquels une des plus grandes figures de l'érudition portugaise de la fin du siècle, António Ribeiro dos Santos, alors Bibliothécaire de l'Université. Deux lettres de Bayer à R. dos Santos 
sont conservées, l'une de 1783, l'autre de 1790. Il est clair qu'une communauté de goûts et d'intérêts rapproche les deux hommes. Ribeiro dos Santos en effet deviendra le premier directeur de la Bibliothèque Nationale de Lisbonne, après une brillante carrière universitaire et administrative, et consacrera sa vie à des recherches littéraires et bibliographiques, produisant une oeuvre considérable avant de disparaître en 1818. (167) Ferreira Gordo, dont il était grand ami, prendra sa succession à la tête de la Bibliothèque Nationale. Le rapprochement de ces trois noms, F. Pérez Bayer, A. Ribeiro dos Santos, J. Ferreira Gordo, souligne l'importance des grands archivistes et conservateurs, à la fois rassembleurs et diffuseurs de culture. Leurs méthodes et leurs objectifs se développeront pleinement avec le $X I X e$ siècle. Et Cenáculo, en donnant une partie de ses livres à R. dos Santos, directeur de la première bibliothèque publique créée à l'échelon national, participe à cette même entreprise, utile et généreuse s'il en fut, qui considère le bénéfice de la collectivité au détriment de la satisfaction individuelle.

Dès le 11 juillet, de Porto, Bayer rappelle à Ribeiro dos Santos qu'il souhaiterait avoir copie d'un incunable dont il a pris connaissance à la cathédrale de Coîmbre et qui est consacré à l'acclamation de la Sainte Relique de ce Saint Thomas de Villanueva pour lequel il a une pieuse dévotion, et qu'il tient pour son tout spécial patron. (168) II demande un copiste "habile, soigneux et de bonne orthographe", et précise que l'on doit transmettre la copie à un certain Manuel Morêt, qui en règlera les frais et "sait à qui l'envoyer à Madrid".(169) Et l'on constate à cette occasion à quel point les érudits de la Péninsule peuvent compter, où qu'ils se trouvent, sur des individus aujourd'hui oubliés, mais dont le modeste labeur a permis un fourmillement de relations d'ordre culturel. Y eut-il d'autre échanges avant l'année 1790 ? On peut en douter, car la deuxième lettre accuse essentiellement réception du mot de recommandation remis par $R$. dos Santos à Ferreira Gordo pour Bayer. II sera reçu, répond le bibliothécaire de Carlos III, avec d'autant plus d'égards qu'il appartient à l'Université de Coîmbre. "Rien, jamais" en effet, s'écrie-t-Il ensuite, "n'effacera de ma mémoire les honneurs dont j'ai été l'objet". Et d'évoquer avec émotion les "vacances conimbrigiennes" de l'été 83.(170)

Il est donc probable qu'il s'est agi d'un échange ponctuel, cependant chargé de sens justement, peut-être, à cause du laps de temps écoulé. Car cette seconde lettre porte malgré sa singularité et son caractère circonstanciel, la marque d'un rapport de sympathie et de confiance non négligeable: Ferreira Gordo aurait été hébergé par Bayer, si celui-ci n'avait pas sa maison occupée par des neveux. En tout cas, le diplomate pourra consulter les manuscrits qui l'intéressent et trouvera un appui sûr à toutes ses démarches. Bayer conclut sur la sombre actualité de la capitale espagnole, le terrible incendie de la Plaza Mayor qui a brûlé deux cents maisons, six 
cents appartements, une église, non sans tuer des gens et ruiner des biens:

"espectaculo á la verdad funesto y lastimero. Se hà visto para algun consuelo de tantos miserables como iban despavoridos y desnudos por las calles sin casa ni hogar á aquella hora, la inimitable piedad de nuestro Soberano y del Pueblo Matritense: dejaron muchos sus camas, para que se albergassen otros. Quis cladem illius noctis!".(171)

Une fois encore, on est à même d'apprécier le rôle du rapport épistolaire, qui semble presque abolir le temps, l'espace, pour se situer dans un éternel présent, une actualité sans cesse renouvelable, une proximité du coeur et de l'esprit qui éclipse celle des corps, pourtant ainsi revivifiée malgré sa brièveté.

D'autre part, la lettre apparaît de plus en plus nettement comme le sésame des contacts culturels, symbolisant le pouvoir de l'esprit et de l'écrit, pouvoir qui demeure après la mort même des correspondants: Cornide se rendra au Portugal dans le sillage de Bayer alors que celui-ci a disparu depuis six ans. Il était d'ailleurs en relations avec Ribeiro dos Santos depuis 1785, probablement sur les conseils de l'orientaliste.(172)

Quels bilans tirer des deux voyages de Francisco Pérez Bayer au Portugal après ce trop bref compte rendu?

On en distinguera de divers ordres, à commencer par une prosaïque considération matérielle: l'édition critique du Diario s'impose, et elle devrait s'accompagner des variantes offertes par l'Extracto, et surtour des magnifiques dessins qui l'ornent et font parfois revivre des monuments disparus.

En deuxième lieu, c'est la très forte personnalité de Pérez Bayer qui retiendra mon attention. Certes, bien des hommes de son temps peuvent lui être comparés par la formation, la carrière, les centres d'intérêt, le goût de la connaissance. Mais il force l'admiration par sa finesse et son objectivité, déployant un éventail de dons que l'âge n'a fait que dévolopper, non sans lui assurer une étonnante robustesse. Courageux (on l'a vu avec l'épisode de Coruche, et ce n'est qu'un exemple), bon (toujours préoccupé de ses gens, apitoyé sur le sort des Morenas), spontané (n'hésitant pas à improviser au violon, à réciter de mémoire des vers latins), il se fait aisément pardonner son péché mignon, la gourmandise (le petit chocolat...), avatar de cet éclectisme des sens qui lui fait aimer la musique, la peinture, les belles choses, dans une perspective d'harmonie et d'équilibre parfaitement en accord avec les options de son époque. Cet homme riche peut paraître prodigue, mais c'est qu'il est à la fois conscient de son rang et de sa mission, et possédé de l'importance d'une bonne ou mauvaise utilisation des biens. 
Ses minutieuses observations font toujours appel à des points de comparaison, témoignant d'un remarquable souci de l'impartialité et de la relativité. L'Italie, Valence sa patrie, Madrid capitale de son pays, sont ainsi toujours à l'arrière-plan de ses considérations, leur donnant toute la crédibilité nécessaire, quand bien même ce serait à l'avantage du Portugal, ce qui est souvent le cas. D'autre part, s'il fait reposer la vérité historique sur l'exploitation scientifique des vestiges exemplaires du passé, il ne se laisse pas abuser par des antiquités douteuses ou fabriquées, se tenant de par sa naturelle urbanité sur une prudente réserve teintée d'ironie, où se lit d'ailleurs une conscience aiguë de ses propres mérites.

Je n'hésiterai donc pas à dire qu'il fait honneur à son siècle, à son pays et à la postérité, laissant de lui une image conforme à celle du nouvel homme voulu par les Lumières en Europe.

Des éléments d'information qu'il nous a transmis, on s'est jusqu'ici essentiellement attaché aux résultats de son labeur archéologique et numismatique, qui s'inscrivent au firmament de l'exégèse du passé étudié dans sa vérité historique, par la recherche méthodique des origines de l'homme alliée au souci d'un retour aux sources. On pressent une double tension dans cette démarche épistémologique, qui engage à la fois la problématique d'une identité primitive, fondée en particulier sur la commune latinité, et celle de la quête d'une définition nationale spécifique ressentie comme une nécessité de l'avenir. Elle a enfin ce mérite fondamental d'introduire le nouvel esprit critique sur un mode jrréfutable, à un moment capital pour l'interrogation formulée par les théologiens au lendemain de séisme de 1755.

Aujourd'hui la lecture du journal de voyage de Pérez Bayer reçoit un nouvel éclairage, à la fois par une réorientation des perspectives due à un intérêt toujours plus marqué pour la réalité quotidienne des époques révolues comme à l'insertion de toute production dans un ensemble européen, et par la projection qu'autorisent les correspondances, inédites ou non, considérées dans la complexité extrêmement logique de leur réseau.

A la lumière de ces données, j'ai cherché à montrer avec quelle précision Pérez Bayer nous renseignait sur les conditions matérielles du voyage à son époque, dans une optique péninsulaire qui donne à l'Espagne et au Portugal des traits communs, parfois comparables à ceux qui caractérisent les nations en voie de modernisation, mais le plus souvent décalés par rapport à elles, et faít aussi ressortir leur mutuelle autonomie, dans le domaine de la législation, du niveau de vie, ainsi que leurs différences, au plan des moeurs ou simplement du climat. C'est là une vision sensible, nuancée, qui change des jugements à l'emporte-pièces, ou des étonnements de Candides, généralement produits par les visiteurs étrangers. Elle suggère le maintien, dont on ne sait s'il faut le qualifier de surprenant, 
d'une solidarité quasi-fraternelle entre deux pays que leur histoire a constamment unis et opposés.

D'autre part, Pérez Bayer apparaît désormais comme l'une des pièces de l'échiquier relationnel Espagne-Portugal, par sa rencontre avec Manuel do Cenáculo, et la conformité de leurs tempéraments et de leurs options. Autour d'eux se profilent d'autres individualités importantes, comme Pereira de Figueiredo, João de Sousa, Ribeiro dos Santos, ou Joaquim Ferreira Gordo pour le Portugal, Muñoz et Cornide Saavedra pour l'Espagne, non sans que la grande ombre de Mayáns préside à ces fructueux échanges, qu'un Campomanes cristallise à l'échelon de l'Académie d'Histoire, voire du Conseil de Castille, car il s'agit bien de rencontre entre les élites culturelles et par là même politiques des deux pays de la Péninsule. Ce réseau littéraire et scientifique dispose d'autres intermédiaires, que leur position sociale a rendus célèbres pour des raisons diverses, des diplomates, com. me Aires de Sá e Melo, le comte de Fernán Núñez, des hommes politiques comme Angeja; ou que leurs nobles aspirations tirent aujourd'hui de l'oubli, tels Caetano da Siva, Siqueira, Villaamil, etc. Appartenant souvent à la classe moyenne cultivèe, ils se recrutent aussi dans la noblesse èclairée -clergé inclus-, revenue à l'honneur après la disgrâce de Pombal, et confirment l'importance du rôle joué par ces groupes sociaux dans la promotion et la diffusion de la culture moderne. Le livre est au coeur de leurs préoccupations, qu'ils font circuler ou exposent dans de belles salles, et qui constitue, pourrait-on dire, le premier interlocuteur des dialogues engagés de chaque côté de la frontière. Il permet en effet de se ranger dans une famille d'esprits et de renier des appartenances obsolètes, et marque la primauté de l'ècrit, affirmèe d'autre part dans la lettre: celle-ci, véhicule de l'information, de la culture, mais aussi de l'amitié donne à l'écrit un statut nouveau, qui privilégie le circonstanciel, le pragmatique, le quotidien, à l'image du journal de voyage tenu par Bayer.

Enfin une vision nuancée du Portugal post-pombalin nous est proposée, qui montre sans doute clairement les limites du "Revirement", mais souligne aussi l'effritement progressif du régime antérieur. La Lisbonne visitée par Francisco Pérez Bayer, que les plans du Marquis continuent de régir et que domine le symbole de la statue équestre, s'infléchit dans le sens d'une architecture moins rectiligne, plus sinueuse, qui trouve en Queluz, le petit Versailles, le haut-lieu de la noblesse, sa plus frappante interprétation. Le musée du marquis d'Angeja, successeur de Pombal, éblouit par sa richesse, son raffinement, sa somptuosité; en revanche, la bibliothèque de la Real Mesa Censória, qui devait être l'instrument culturel par excellence du despote éclairé, est devenue un poussiéreux grenier: elle sera réorganisée pour constituer la Bibliothéque Royale, une création de $\mathrm{D}$. Maria I paradoxalement héritée des idées du favori de son père. L'Université de Coîmbre fonctionne dans le cadre voulu par son réformateur, mais ne doit-on pas estimer qu'elle a été récupérée par la nouvelle souveraine, qui 
en contrôle les professeurs, en parachève la législation et en finance le développement avec un soin jaloux? Se dégage donc l'impression d'un pays qui continue d'exposer une brillante façade, à l'image de sa capitale en reconstruction, mais qui a renoncé aux réalisations de prestige qui éblouissaient, dix ans auparavant, Rafael Mohedano: grandioses travaux d'Etat, installations manufacturières, organes directeurs du centralisme éclairé, abandonnés pour raison financières ou idéologiques.

Pour l'ancienne équipe au pouvoir, qui gravite encore autour de Cenáculo, c'est une preuve de décadence, dont la signification pour le Portugal est celle d'un rendez-vous manqué avec l'Europe nouvelle. L'érudit valencien Francisco Pérez Bayer pense, lui aussi, que son pays a laissé échapper la chance de la modernité et du progrès. Pourtant, deux cents ans après, le lecteur reste admiratif devant le mérite, la hauteur de vues et la ténacité d'hommes de sa trempe, qui furent nombreux à l'époque des Lumières dans la Péninsule Ibérique tout entière. 


\section{NOTES}

(1) G. Mayáns à Cenáculo. Valencia, 31-XII-1768. Biblioteca Pública de Evora (BPE), CXXVIII/1,8, f. ${ }^{\circ} 6$. L'orthographe originale a été conservée pour l'ensemble des citations.

(2) II semble s'agir d'un premier épisode dans l'affaire de la Grammaire Latine de Mayáns. L'érudit espérait voir adopter son ouvrage dans toutes les universités espagnoles, mais il rencontre l'opposition des amis de Juan de Iriarte, auteur lui-mẽme d'un travail similaire en vers. Bayer, comme ami et compatriote de Mayáns, serait resté longtemps son partisan, mais aurait fini par céder aux pressions et par approuver la Grammaire d'Iriarte, obtenant en échange l'autorisation de publier un ouvrage de l'Infant Gabriel, traduction des Oeuvres de Salluste, qu'il accompagnait d'une Dissertation personnelle sur l'alphabet et la langue des Phéniciens (Sempere y Guarinos, Ensayo de una biblioteca razonada de los mejores escritores del reinado de Carlos III, Madrid, Gredos, éd. fac-simile, I, pp. 194-195). La Grammaire d'Iriarte fut publiée après sa mort en 1771 , aussi l'allusion à une grammaire des Ecoles Pies imprimée par les soins de Bayer au cours de l'année 1768 à Valence apporte-t-elle un éclairage nouveau. Le Conseil de Castille décréta en 1771 que la Grammaire de Mayáns serait texte officiel dans les universités de la Couronne d'Aragon, mais cette décision ne fut guère suivie d'exécution. L'ouvrage de Mayáns était pourtant conçu dans un esprit essentiellement pratique, tout à fait en accord avec l'esprit du temps: successivement la morphologie, la syntaxe et la prosodie étaient exposées aux élèves, qui devaient pouvoir retrouver par eux-mêmes les formes correctes d'un texte latin, puisqu'on leur proposait la traduction espagnole afin qu'ils le restituassent dans la langue originale. Cenáculo en fait grand cas et la montre à Pombal (Cenáculo à G. Mayáns, Lisbonne, 11-XII-1769, B. A. H. M., Biblioteca de Corpus Christi, T. 89), mais au Portugal par décret royal de 1759, c'est la grammaire de l'Oratoire, et plus précisément celle d'António Pereira de Figueiredo qui est imposée à toutes les écoles officielles de la Métropole et d'Outre-Mer, et Cenáculo échouera dans sa tentative d'imposer celle de Mayáns.

Sur toute la question de la rivalité Mayáns-Iriarte, v. Antonio Mestre, Historia, fueros y actitudes politicas. Mayáns y la historiografía del XVIII. Valencia, Publicaciones del Ayuntamiento de Oliva, 1970, 603 p., pp. 430-437.

(3) G. Mayáns à Cenáculo. Valencia, 31-XII-1768, BPE, CXXVII1/1-8, f. ${ }^{\circ}$ 6. Gente Social: Jesuites, chez Mayáns.

(4) Du même au même. Valencia, 11-IX-1773. Ibid., f. 69. L'Infant Gabriel, mort en 1778, appartint à l'Académie des Beaux-Arts de S. Fernando, et à l'Académie de la Langue.

(5) J. A. Mayáns à Cenáculo. Valencia, 31-V-1783. Ibid., f. 121.

(6) Id. ibid.

(7) José Leite de Vasconcelos, "Viagem de Pérez Bayer em Portugal em 1782", O Archeologo Português, XXIV (1920), pp. 108-176. Toutes les références au journal de voyage de Bayer seront extraites de cette édition, faite avec beaucoup de soin. On se contentera de la mention: Di(ario), suivie du numéro de la page.

(8) F. Pérez Bayer à J. A. Mayáns. Madrid, 24-XII-1782. Epistolario Mayáns-Pérez Bayer. Transcripción, notas y estudio preliminar de Antonio Mestre. Valencia, Publicaciones del Ayuntamiento de Oliva, 1977, p. 413.

(9) Diario, 119-120.

(10) Cenáculo à J. A. Mayáns. Beja, 4-1I-1789, Biblioteca Municipal de Valencia, B. M. Va., Serrano Morales, $6811,2 .^{\circ} \mathrm{leg} .^{\circ}$

(11) J. A. Mayáns à Cenáculo. Valencia, 19-VI-1787, BPE, CXXVIII/1-8, f. ${ }^{\circ} 148$.

(12) A. Mestre, Historia, fueros, etc. op. cit., pp. 435-436, montre clairement que Bayer impose à Valence ses amis et alliés comme Joaquin Segarra, qui gênera depuis le Coliège de San Pablo l'action de Juan Antonio comme recteur de l'Université. Dans llustración y reforma de la iglesia. Pensamiento político-religioso de don Gregorio Mayáns y Siscar (1699-1781), Valencia, Publicaciones del Ayuntamiento de Oliva, 1968, 509 p., le même auteur fait reposer ces luttes sur des différences doctrinales entre thomistes (parmi lesquels Bayer) et anti-thomistes (les frères Mayáns). V. pp. 440-441. 
(13) Rafael Mohedano à Cenáculo. Madrid, 6-ll-1784. BPE, CXXVIII/1-6, f. 269.

(14) Du même au même. Madrid, 12-III-1784. Ibid., f. ${ }^{\circ} 271$. II s'agit de l'ouvrage De Nummis Hebraeo-Samaritanis. Valence, 1781.

(15) José Luis Soto Pérez, "Un arabista del siglo XVIII: el franciscano Fr. José Banqueri, T. O. R. (1745-1818)", Boletín de Centro de Estudios del Siglo XVIII, Oviedo, Cátedra Feijoo, pp. 147-178, sur le voyage de Mohedano plus précisément, pp. 156-162. Et Marie-Hélène Piwnik, "Voyage au Portugal de quatre religieux espagnols du Tiers-Ordre de la Pénitence", Bulletin des études portugajses et brésiliennes, Nouvelle série, T. 39 et 40, 1978-1979, pp. 25-84.

(16) Léon Bourdon, "Relations littéraires portugaises de Juan Bautista Muñoz (1784-1799)n, Arquivos do Centro Cultural Portugués, VIil (1974), pp. 405-536.

(17) Fidelino de Figueiredo ne fait rien moins de Cornide qu'un espion: Viajantes espanhóis em Portugal, São Paulo, 1947.

(18) Parmi les récits de voyage étroitement contemporains de celui de Bayer, et hormis les relations de Cornide, citons: William Beckford, The Journal of ... in Portugal and Spain (17871788), éd. Boyd Alexander, Londres, 1954, Arthur William Costigan, Sketches of society and manners in Portugal in a series of letters, London, 1787, mais aussi William Dalrymple, Travels through Spain and Portugal in 1774, London, 1777, Heinrich Friedrich Link, Voyage en Portugal depuis 1797 jusqu'en 1799, trad. de l'allemand, 2 vol., Paris, 1803, James Murphy, Travels in Portugal through the provinces of Entre Douro o Minho, Beira, Estremadura and Alem Tejo dans les années 1789 et 1790, illustrated with plates, Londres, 1795, Robert Southey, Journals of a residence in Portugal 1800-1801 and a visit to France 1838, ed. Adolfo Cabral, Oxford, 1960, et enfin Richard Twiss, Travels through Portugal and Spain in 1772 and 1773, Dublin, 2 vol. 1775. A consulter également la récente publication du Centre Culturel Portugais de la Fondation Gulbenkian, Marquis de Bombelles, Journal d'un Ambassadeur de France au Portugal, 1786-1788, Paris, PUF, 1979, $398 \mathrm{p}$.

Pour une mise en parallèle avec la réalité espagnole perçue par les voyageurs étrangers, Francisco Aguilar Piñal, "Relatos de viajes de extranjeros por la España del siglo XVIII. Estudios realizados hasta el presente", Boces, XVIII, núms. 4 et 5, Oviedo, 1977, pp. 203-208.

En approche théorique de la signification du voyage au XVIII ${ }^{\circ}$ siècle, Rafael Olaechea, uUna viajera rusa del XVIII en los Pirineos franceses", Anales de la Universidad de Alicante, n. ${ }^{\circ} 2$, 1982, pp. 223-250.

(19) Sur cette question de la réforme des Colegios Mayores et du rôle joué par Bayer, François Lopez, Juan Pablo Forner et la crise de la conscience espagnole au XVIII ${ }^{\circ}$ siecle, Université de Lille III, 1977, 725 p., pp. 221-230.

(20) On peut tirer des éléments de biographie et de bibliographie de Sempere y Guarinos, op. cit., I, pp. 189-202, et de Juan Pastor Fuster, Biblioteca valenciana de los escritores que florecieron hasta nuestros dias, Valencia, 1830, II, pp. 141-162.

(21) $V$. notes 7 et 8.

(22) BPE, CXXVIII/1-9, núms. 1770 à 1777: F. Pérez Bayer à Cenáculo, 8 lettres autographes, Aldeia Galega, 12-XI-1782; Lisbonne, 15 et 25-XI-1782; Madrid, 9-1-1783; Ponte de Murcela, 1-VII1783, avec un post-scriptum du 7-VII; Porto, 10-VII-1783; Madrid, 26-VIII-1784, 18-VIII-1790; ASL, $178 \mathrm{~V}$ (Bibliothèque de l'Académie des Sciences de Lisbonne): F. Pérez Bayer à V. Salgado, 1 lettre autographe, Madrid, 31-XII-1782. BNL, Cod., 6796 (Bibliothèque Nationale de Lisbonne): F. Pérez Bayer à A. Ribeiro dos Santos, 2 lettres autographes, Porto, 11-VII-1783 et Madrid, 19-VIII1790. Epistolario Mayáns-Pérez Bayer, op. cit., lettres de Madrid des 24-XII-1782, 23 et 30-V-1783, respectivement pp. 413,414 et 416.

(23) BPE, CXXVIII/2-9. M. do Cenáculo à Bayer, 6 lettres autographes: Beja, 19-1I, 19-VII et 11-XI-1783, respectivement fos 370, 380 et 383; Beja, 27-IV, et 8-X-1784, fols. 401 et 393; Beja, 7-XI$1785, f^{\circ} 409$.

BPE, CXXVIII/2-10. M. do Cenáculo à Bayer, 2 lettres autographes: Beja, 6-X-1790, $f^{\circ} 3 \mathrm{v}$, et Sines, septembre $1792, f^{\circ} 33$.

(24) BPE, CXXIX/1-18, 4-XI-1782 sqq. 
(25) BPE, CXXVIII/1-2. Vicente Salgado à Cenáculo: Aldeia Galega, 12-XI-1782, f० 156; Lisbonne, 18 et 25-XI-1782, fos 140 et 128; Lisbonne, 2,16 et $30-X \mid 1-1782$, fos 142, 146 et 154; Lisbonne, 14, 15, 21 et 28-I-1783, fos 162, 164, 167 et 171; Lisbonne, 4-II-1783, $f^{\circ}$ 174; Lisbonne, 22-IV$1783, f^{\circ} 193$.

(26) BPE, CXXVII/1-2, n. ${ }^{\circ}$ 257. F. António Martins (son frère) à Cenáculo: Beja, 3-X।-1782. BPE, CXXVII/2-4, п. ${ }^{\circ}$ 3017; José Maldonado (notable) à Cenáculo: Evora, 11-XI-1782. BPE, CXXVII/1-11, n. ${ }^{\circ}$ 2032. João de Aguilar de Meneses (Inquisiteur d'Evora) à Cenáculo: Evora, 12-XI1782. BPE, CXXVII/2-4, núms. 2960 et 2961. Ignácio da Rocha Peniz (professeur de l'Université de Coïmbre) à Cenáculo: Coïmbre, 21-VII et 29-IX-1783.

Je signale à la fin de ce parcours de références que la Bibliothèque d'Evora dispose de deux catalogues de manuscrits très bien faits. Le premier est celui de Joaquim Heliodoro da Cunha Rivara, Catálogo dos $\mathrm{ms}$. da Biblioteca Eborense. II constitue un premier classement de l'ensemble des ms. conservés. Le second, Catálogo da correspondência dirigida a Fr. Manuel do Cenáculo Vilas Boas, établi par Nobre de Gusmão concerne les correspondances adressées à Cenáculo exclusivement. Classées par ordre de prénom des correspondants, les lettres sont présentées avec un court résumé de leur contenu. Malheureusement le labeur acharné de N. de Gusmão s'est arrêté avec sa regrettée disparition, et le catalogue s'interrompt au milieu de la lettre R. Le nombre des correspondances espagnoles est proprement impressionnant. Jacques Marcadé en donne une idée dans son travall Frei Manuel do Cenáculo Vilas Boas, évêque de Beja, archevêque d'Evora, 1770-1814, Fundação Calouste Gulbenkian, Paris, 1978, 592 p., à la p. 383, n. 108.

(27) Cod. 342: Diario das primeiras viagens que fez pelas terras de Portugal D. Francisco Perez Bayer Arcediago da Igreja Cathedral de Valencia, Mestre dos Infantes de Espanha, $e$ Bibliothecario Mayor da Real Bibliotheca de Madrid copiado de um Ms. que tem D. Jozé Cornide de Saavedra. Leite de Vasconcelos fait état d'une lettre de Menéndez Pidal, qui était son ami, estimant en 1913 que le ms. est à ce jour inédit. II signale l'existence d'un extrait du voyage, effectué par V. Salgado et conservé à l'ASL (ms. 685 V), dont il n'y a rien à dire si ce n'est que le secrétaire de Cenáculo coupe les passages que l'on considère aujourd'hui comme particulièrement intéressants, savoureux ou pittoresques, pour n'en conserver que les épisodes scientifiques.

(28) Viaje a Portugal en 1782, ms. 9-29-6. 5974. 70 p., avec la mention: "Esta copia se conoce que fue sacada para don José Cornide. Debió servirle en el viaje que también hizo a Portugal, entre cuyos papeles estaba».

(29) II semble que ce soit désormais le seul document concernant la partie espagnole du voyage. Selon le principe de l'Extrait dans sa totalité, on n'a affaire à peu de choses près qu'à l'aspect archéologique du voyage, aucun détail matériel, en particulier, n'étant conservé, sur les raisons du voyage, le financement de l'expédition, ses membres, etc. C'est un grand vo!. in-4. de 298 fos recto/verso.

Dans son Journal, Bayer fait allusion au motif de son voyage, de façon vague: "Venimos ultimamente á hablar del obgeto de mi viaje á Portugal: Expusele succintamente, y que ya que havia venido á Andalucia y al confin del Reyno de Sevilla por los motivos que expuse en el Prologo de la primera parte (disparu de l'Extracto), y acercadome á las Villas de Aracena, Alhafar y el Castaño por adquirir noticias de Benito Arias Montano (que son la frontera de Portugal) me dexé facilmente persuadir de la vecindad» (Di., 120). L'Extracto précise dans l'Advertencia que seul le voyage en Andalousie était mision de l'Académie. C'est pour cette raison, dit-il, que le parcours antérieur (Valencia, Murcia, Cartagena) n'y figure point. Pourtant, l'Extracto inclut l'expédition au Portugal...

(30) p.

(31) BPE, CXXVIII/1-9, n. ${ }^{\circ}$ 1774. Ponte de Murcela, 1-VII-1783.

(32) BPE, CXXVII/1-11, n. ${ }^{\circ}$ 2032, Aguilar de Meneses à Cenáculo, Evora, 12-XI-1782: "Talvez (Bayer) mude a idéa de passár de $L x^{a} p^{a}$ Coimbra, Porto, em vir dár hum giro ao Algarve".

(33) BPE, CXXVIII/1-9, n.: 1774. Bayer á Cenáculo, Ponte da Murcela, 1-VII-1783: "Enfermé de una distilacion tan fuerte al cañon izquierdo de la nariz que temî y temieron los inteligentes que degenerasse en un funesto cancro". 
(34) Ceci n'étalt pas rare à l'époque et on lit sous la plume de Tollenare quelques années plus tard: “Nous voyageons sur des mules dont le pied est sûr; il n'y a point de mauvais pas pour elles. II serait impossible de faire en voiture le chemin que nous suivons. Il y en a un autre un peu plus long et, dit-on, à peu près practicable pour des chaises de poste. Nous rencontrons des voyageurs montés comme nous sur des mules, et quelquefois des litières: ce sont des moines ou des dames qui se font transporter de cette manière", L. F. de Tollenare, Notes dominicales prises pendant un voyage en Portugal et au Brésil en 1816, 1817 et 1818, Ed. et commentaire de Léon Bourdon, Paris, Fundação Calouste Gulbenkian, PUF, Paris, 1971, 3 vol., vol. 1, p. 88. J'ai acquis la certitude de cette façon de voyager pour Bayer et son escorte par divers recoupements, en particulier lorsqu'il précise avoir gagné Beja "par un sentier qui n'admet pas les roues» (Diario, 113), dit "monter sur son cheval" (ib., 130), craint de devoir passer la nuit à la belle étoile (ib., 171), est obligé de se changer des pieds à la tête en arrivant à Elvas tant il est trempé (ib., 174). D'autre part, l'allure adoptée est le pas d'après les distances parcourues, généralement six à sept lieues par jour, en six ou sept heures quand le temps le permet, soit de trente á trente-cinq kilomètres, souvent d'une traite, et en partant tôt le matin: huit heures est une heure tardive (ib., 171). Le contemporain Diccionario de Autoridades définit la lieue comme cla distance que l'on parcourt à pied en une heure". Je n'ai presque aucune indication sur les bagages transportés, sauf le fait que les voyageurs sont une fois contraints de se nourrir uavec du fromage de la besacen (Di., 113). A. Balbi, Essai statistique sur le Royaume de Portugal et d'Algarve comparé aux autre Etats de l'Europe, 2 vol. Paris, 1822, cit. par L. Bourdon, Notes doninicales... op. cit., p. 91, n. 1, affirme: "Les personnes qui voyagent en voiture sont dans l'usage de porter avec elles tout ce qui leut leur être nécessaire: draps, matelas..... Si Bayer et les siens n'en arrivent pas là, ils sont cependant sûrement lourdement chargés, même si l'incursion au Portugal n'a pas été pré. vue. En ce qui concerne les montures, les hommes à pied, v. plus bas, n. 40.

(35) Parfois il s'agissait de simples pistes (carril, dit Bayer, Diario, passim). Comment s'orientaient les voyageurs? La boussole, le soleil, devaient jouer leur rôle. D'autre part, les progrès de la géographie espagnole sont notoires en ce qui concerne le Portugal depuis la guerre de 1762, car il faut bien penser qu'il s'agit pour l'essentiel d'une science aux applications militaires. La Gaceta de Madrid, à partir du n..$^{\circ} 7$ de 1762 annonce des cartes par provinces du Portugal, mises au point par D. Tomás López, géographe de Sa Majesté, qui existent en grand format et en modèle de poche: "cortado en quarterones, y colocado en lienzo para la faltriquera". A l'époque en France, des cartes de ce type existent, au $1 / 80.000$, sous forme de carnets entoilés dépliables. II y avait, bien sûr, les renseignements demandés en chemin, dont on a la preuve par ce passage du journal de Bayer: "(sur la route de Coruche) no viamos sino manadas de gamos, sin un alma á quien preguntar ni chozo ni caserio: Jamás pudimos ver el lugar de Gloria, ni un palmo de tierra labrada que nos huviera guiado á éln (p. 169).

(36) Je suis confirmée dans cette impression par Balbi, op. cit., qui estime que si "les auberges (portugaises) sont généralement mauvaises», elles sont "préférables sous tous les rapports à celles de l'Espagne méridionale" (p. 477). Link, Voyage, op. cit., III, 292, déclare également: "toutes les auberges depuis Elvas jusqu'à Lisbonne sont médiocres et meilleures que celles d'Espagne». J'ai conservé dans ce passage les transcriptions de Bayer, qui hispanise tous les noms.

(37) BPE, CXXVIII/1-9, n. ${ }^{\circ}$ 1776. Bayer à Cenáculo, Madrid, 26-VIII-1784. Bayer admire la sobriété bien connue de Cenáculo: „Pidió á las diez su desayuno (pues nada havia aún tomado), traxeronle un vaso grande de agua y un panete: tomó un canterillo y lo comió, y bevió un poco de agua. Et haec de tota littera textus asta las tres de la tarde en que su IIIma. comen (Di., 121).

(38) BPE, CXXIX/1-8, 4-XI-1782. La distorsion entre le nombre des montures et celui des voyageurs pourraił s'expliquer de la façon suivante: Bayer et le dessinateur seraient à cheval et disposeraient d'une béte de réserve, trois demestiques iraient à dos de mulet, et deux autres se déplaceraient à pied en aidant à la progression du groupe. Creados de cima signifierait alors non pas seulement "domestiques de rang supérieur", mais plutôt "domestiques montés", et creados de baixo aurait le sens de “domestiques à pied» davantage encore que celui de "domestiques de rang inférieurn. On a vu (n. 34) que les évaluations horaires par rapport aux distances parcourues amènent à conclure à un déplacement au pas de l'escorte. C'est ainsi que les voya- 
geurs mettent sept heures avec une courte halte pour aller de Coruche à Mora (un peu moins de sept lieues, quelque trente cinq kilomètres).

(39) Dans l'Extracto, on trouve une précision supplémentaire (ce qui est l'exception): “me dio otro Passaporte en lengua Portuguesa, con su Escudo de Armas del Rey de Portugal. Díle las gracias y me despedí». Est-ce le même laissez-passer, appelé guia dans le journal?

(40) La Real Mesa Censória, créée par Pombal le 5 avril 1768, remplaçait trois juridictions qui remontaient au XVI' siècle: le Saint Office (censure pontificale), l'Ordinaire du Diocése (censure épiscopale), et le Desembargo do Paço (censure royale). Le nouveau tribunal est un modèle institutionnel intéressant, que Rafael Mohedano, par exemple, veut connaître dans le détail. Le président, qui devait être un homme "sage et autorisé», aussi versé en Droit Civil qu'en Droit Canon, s'entourait de sept députés ordinaires, théologiens, juristes et politiques, de préférence docteurs de l'Université de Coïmbre, pris dans le Conseil du Royaume et au sein des tribunaux des différents ordres. Il y avait aussi des députés extraordinaires, et un secrétaire. Un seul des députés devait appartenir au tribunal de l'Inquisition de Lisbonne, encore ses attributions étaient-elles limitées dans le texte de la loi. Cet appareil d'Etat survit à Pombal jusqu'en 1794, date a laquelle D. Maria I rétablit les juridictions antérieures. Mais on s'accorde à dire que ce retour en arrière s'opéra dans le cadre et selon les critères somme toute à jamais institués par le Marquis. Sur cette question, v. José Timóteo da Silva Bastos, História da Censura Intelectual em Portugal, Coimbra, Imprensa da Universidade 1926, et Maria Adelaide Salvador Marques, A Real Mesa Censória e a Cultura Nacional, Coimbra, 1963.

(41) Pragmatique du 14 septembre 1771, complétant celle du 4 juillet 1770 (Novisima recopilacion de las leyes de España, Madrid, 1805, IX, XII, 19-21) et interdisant l'entrée en Espagne de tous les tissus de coton, indiennes, mousselines, etc. Il semble que pour les soieries il fallle remonter à 1718, Real Decreto du 17 septembre (Nov. rec., IX, XII, 7), qui interdit l'entrée de soies et autres tissus en provenance de Chine et d'Asie.

Au Portugal, c'est seulement en 1788 que l'importation des soieries ouvrées est interdite, celle des soieries unies demeurant autorisée moyennant le droit habituel de $30 \%$. Ces đernières, sauf celles qui étaient en provenance d'Angleterre, ne furent interdites d'importation qu'en 1816. Sur cette question et les problèmes de la Real Fábrica de Sedas, L. Bourdon, Notes dominicales, op. cit., I, pp. 182-183.

(42) Le rôle joué par les diplomates dans la diffusion des livres interdits est mis en lumière sur des exemples précis par Luis de Oliveira Ramos, "Da aquisição de livros proibidos nos fins do seculo XVIII (Casos Portugueses)", Revista da Faculdade de Letras do Porto. (Série de História, vol. IV-V, Porto, 1973-1974). II indique par exemple que chez le libraire français Dubié, installé au Chiado, on saisit en 1791 une caisse de livres interdits qui porte, non point l'adresse du libraire, mais celle du comte de Challons, alors ambassadeur de France à Lisbonne, ce qui permet à Dubié de prétendre que les livres luis ont été remis à seule fin de reliure.

(43) II fait déjả lire son récit aux personnalités portugaises qu'il rencontre. "V. E. faz papel em todos os dias do seu Diarion, écrit Salgado à Cenáculo le 25-XI-1782 (BPE, CXXVIII/1-2, f. ${ }^{\circ}$ 128, de Lisbonne). Les religieux de Mafra en sont gratifiés (Di., 165). Cenáculo commente modestement: "Elle (J. A. Mayáns) diz a pena de oiro com que V. S. Ilma. enfeita e honra quanto escreve no seo diario, capaz, na aceitação e no effeito, das vistas mais sublimes do mundo. Volva V.S. IIma. a esta sua caza para dezenganarse que eu não sou homem do seo diario, que os meos conhecimentos me hazem ser varão de dezejos, que em tanta variedade de cuidados só posso entender - apenas - os outros que não imito». Cenáculo a Bayer. Beja, 19-VII-1783. BPE, CXXVIII/2-9, f. 380 .

(44) Soit le revenu annuel d'une trentaine de familles paysannes de Santa Margarida do Sado, village de la région (cit. par Marcadé, Frei Manuel, p. 239).

(45) BPE, CXXVIII/1-9, n. ${ }^{\circ}$ 1771. Bayer à Cenáculo, Lisbonne, 15-XI-1782. Pour l'aspect improvisé du voyage, v. n. 29.

(46) "quiz vestirse de roupas Bayer por se interessar com as pessoas de dignidade do seu conhecimento. Eu o conduzi á rua Augusta a caza do Sr. Antonio Duarte que tem obrado com este cavalheiro mais que pedia o interesse que V. E. se propoz. Tem pagado letras, dado dinheiros 
e vai crescendo a divida a medida do seu apetiten. Le commentaire de Salgado n'est guère aimable: il est vrai qu'il se plaint à Cenáculo de ne pas recevoir, lui, assez d'argent de Cenáculo pour traiter Bayer comme il le faudrait... (BPE, CXXVIII/1-2, f. ${ }^{\circ} 140$. V. Salgado à Cenáculo, Lisbonne, 18-XI-1782).

(47) Je ne sais comment interpréter avec exactitude les "frutillas de Indias y de la China" cités p. 151 du Diario. II doit s'agir d'un genre d'épices (Autoridades: "Usan de el Cacáo, que es una frutilla, en lugar de dinero", Pic. Just., f. 113), plutôt que de chapelets (Autoridades: "Se llama tambien una especie de coquillos, de que se hacen rosarios»).

(48) BPE, CXXVIII/1-9, n. ${ }^{\circ}$ 1772. Bayer à Cenáculo, Lisbonne, 25-XI-1782.

(49) BPE, CXXVIII/1-2, f. ${ }^{\circ} 128$. V. Salgado à Cenáculo, Lisbonne, 25-XI-1782.

(50) N. Glendinning, Historia de la Literatura Española, El siglo XVIII, Ed. Ariel, Barcelona, Caracas, Mexico, 1978, p. 47.

(51) Vicens Vives, Historia de España y América, Ed. V. Vives, Barcelona, 1961, T. IV, p. 47. C'est un salaire insuffisant pour vivre à l'aise à Barcelone.

(52) Cit. par P. J. Guinard, Bulletin Hispanique, T. LIX, 2, avril-juin 1957, "Le livre dans la péninsule ibérique au XVIII ${ }^{\circ}$ siècle". V. aussi de F. da Gama Caeiro, "Livros e livreiros franceses em Lisboa nos fins do setecentos e no primeiro quartel do século XIX", Anais da Academia Portuguesa da História, II série, vol. 26, T. II, Lisbonne, 1980, pp. 302-327.

(53) “Ya voi teniendo credito pecuniario en Lisboa porque me hà fiado nuestro Ministro, que estuvo ayer á visitarme y combidarme á su mesa, y ofrecerseme para quanto necessite". BPE, CXXVIII/1-9, n. ${ }^{\circ}$ 1771. Bayer à Cenáculo, Lisbonne, 15-XI-1782.

(54) BPE, CXVIII/1-2, f. ${ }^{\circ} 140$. V. Salgado à Cenáculo, Lisbonne, 18-XI-1782.

(55) BPE, CXXVIII/1-9, n. ${ }^{\circ}$ 1776. Bayer à Cenáculo, Madrid, 26-VIII-1784.

(56) Sur cette figure capitale de l'humanisme éclairé portugais, consulter, outre les classiques ouvrages de F. da Gama Caeiro, Frei Manuel do Cenáculo, Aspectos da sua actuação filosófica, Lisbonne, 1959, 351 p., et de J. Marcadé Frei Manuel etc., op. cit., de ce dernier aLe jansénisme au Portugal (Note d'approche)n, Revista Portuguesa de História, Faculdade de Letras da Universidade de Coimbra, Instituto Histórico, Económico e Social, T. XVIH, Coimbra, 1980.

(57) Cet organisme, créé en 1772, était chargé de collecter un nouvel impōt, dit du Subsídio Literário, destiné à alimenter les réformes pédagogiques pombalines. Je cite J. Marcadé, Frei Manuel etc., p. 77: "c'est une taxe de 1 real par cañada de vin et de 4 réis par cañada d'eau de vie vendues et de 160 réis sur chaque pipe d'eau de vie qui se fabriquait au Portugal ou dans les îles de l'Atlantique. Dans les colonies d'Asie et d'Amérique, la taxe était de 1 real par arrátel de viande vendu et de 10 réis par cañada d'eau de vie fabriquée". Marcadé note qu'Olavide à Séville voulait employer aux mêmes fins les taxes sur les boissons.

(58) C'était la commission qui avait pour objet la réforme des études supérieures, et plus précisément la restructuration de l'Université de Coïmbre. Après sa création par Carta Régia le 23 décembre 1768, elle élabore et fait imprimer le fameux libelle diffamatoire contre la Compagnie de Jésus Compendio Historico do estado da Universidade de Coimbra no tempo dos denominados Jesuitas, Lisbonne, 1772, largement diffusé en Espagne. Cenáculo semble en être l'un des principaux rédacteurs. D'autre part, il participe directement à la mise au point des statuts de la Faculté de Théologie. V. J. Marcadé, Frei Manuel etc., pp. 79-85, et M. H. Piwnik, «Voyage au Portugal de quatre religieux etc.", p. 47, ainsi que "Un épisode des relations intellectuelles entre l'Espagne et le Portugal au XVIII ${ }^{\circ}$ siècle: la correspondance des frères Mohedanos adressée à Manuel do Cenáculo, évêque de Bejan, Arquivos do Centro Cultural Português, XI, Paris, Fundação Calouste Gulbenkian, 1977, p. 243.

(59) J. Marcadé, Frei Manuel etc., pp. 19-21.

(60) Id. ibid. p. 25.

(61) Id. ibid. chap. V-IX.

(62) Je travaille à l'édition de cette correspondance, prévue par le Centre Culturel Portugais de la Fondation Gulbenkian. Elle va de 1768 à 1797 et se trouve essentiellement à Valencia et Evora. 
(63) J. L. Soto Pérez, art. cit. sur José Banqueri, retrace toute la carrière de cet arabisant franciscain, protégé de Casiri et traducteur d'arabe attaché à la Bibliothèque Royale, montrant en particulier les relatifs déboires que lui cause l'éclipse des Mohedanos après la cabale obscurantiste qui les accable à Grenade. V. aussi M. H. Piwnik, art. cit. sur les Mohedanos et sur le Voyage, ainsi que: "Les membres portugais de l'Académie d'Histoire de Madrid au Siècle des Lumières", Arquivos do Centro Cultural Português, XVII, 1982, pp.

(64) Un pâle portrait de Bayer jeune illustre l'article que l'Enciclopedia Espasa Calpe lui consacre, et le certificat des douanes portugaises n'en prend que plus d'intérêt. Le portrait de l'Enciclopedia est sans doute celui qui est cité dans le texte, dû au peintre Joaquín de Inza et conservé à l'Université de Salamanque. Pour ce qui est de Cenáculo, hormis un portrait officiel de António Joaquim Padrão bien connu et qui orne par exemple l'ouvrage de Gama Caeiro cit., on a le témoignage de R. Southey, op. cit:: "little, chearful, large eyed man" (cit. par Marcadé, Frei Manuel etc., p. 201).

(65) BPE, CXXVII/1-2, n. ${ }^{\circ}$ 257. Fr. António Martins à Cenáculo, Beja, 3-XI-1782. Bayer l'appelle Fr. António de la Piedad $(D i, 114)$ mais el faut lire da Soledade. Le frère de Cenáculo fut comme lui Supérieur du Couvent du Jésus, le remplaça dans sa charge de Provincial lors du chapitre de Valence, fut élu Définiteur Général en 1770, et doit être considéré comme l'un de ses collaborateurs les plus étroits, faisant de fréquents séjours à Beja, au moment de visites pastorales par exemple.

(66) BPE, CXXIX/1-8, 4-XI-1782.

(67) Ibid. Cenáculo ne recule pas devant l'éloge métaphorique: "Quando eu fallei ao Sr. Mayáns (Juan Antonio) de V. S. ${ }^{a}$ IIma., expliquei a minha consciencia: eu vi e toquei brilhantes, perolas, muitas pedras preciozas, ellas me dezapareceram dos olnos, mas eu as descubro entre moedas samaritanas que tenho descriptas por boa mãon (il s'agit de l'oeuvre de Bayer de Nummis etc., que celui-ci a envoyée à son ami portugais à son retour à Madrid). Cenáculo à Bayer. Beja, 19-VII-1783, BPE, CXXVIII/2-9, f. ${ }^{\circ} 380$.

(68) Sur cet esprit distingué, qui convainc Bayer que c'est Beja, et non Badajoz, qui est Pax Julia (Diario, 116), v. O Archeologo Português, XVII, 178.

(69) Pour la coilection épigraphique de Cenáculo, v. Marcadé, Frei Manuel, pp. 242-244.

(70) Sur l'estimation de cette bibliothèque, Marcadé, Frei Manuel etc., p. 239.

(71) Cenáculo disposait d'un réseau d'intermédiaires important dans la péninsule et audelà. Le bibliothécaire royal Martínez Pingarrón ainsi que le libraire Barthelemy à Madrid, la librairie Mallén à Valence, les frères Bérard à Séville font parvenir des ouvrages ou entreposent ceux qu'il destine à Mayáns, aux Mohedanos etc. D'autres médiateurs moins connus, comme un Miguel Rubio de Pradas, commissionnaire à Madrid, un Manuel Roiz Arraz, de Badajoz, s'occupent de ses commandes ou expéditions, comme le Portugais João António de Siqueira à Elvas (Correspondance Mayáns-Cenáculo, et lettres des Mohedanos à Cenáculo). Marcadé, Frei Manuel, op. cit., pp. 237-239, évoque le rôle de V. Salgado, acheteur pour Cenáculo chez les libraires de Lisbonne, Borel, Bertrand, du Beux, dont les correspondances, conservées à Evora, attestent des souhaits fort nombreux de leur client tout autant que de ses dettes à leur égard.

(72) L'allusion aux "Godos, etc.", peut renvoyer au Tratado de la regalía de Amortización de Campomanes (1765) qui porte dans son titre la mention acon una noticia de las leyes fundamentales de la Monarquia Española sobre este punto, que empieza con los Godos y se continúa en los varios Estados sucesivos". L'ouvrage est connu au Portugal. Lopes Caldeira, membre portugais de l'Académie d'Histoire de Madrid, en accuse réception à la fin 1766. Campomanes est aussi l'auteur d'une Disertación sobre las leyes y el gobierno de los Godos en España, présentée à l'Adadémie en 1751, et qu'A.-J. da Cunha, un autre Portugais élu à l'Académie madrilène, lui réclame instamment en 1759 (ce travail semble être resté manuscrit). Sur ce point, v. M. H. Piwnik, art. cit. sur "Les membres portugais de l'Académie etc".

La brochure anonyme dont il est question dans la conversation entre Bayer et Cenáculo est intitulée Avisos al Maestro de escrivir, et en marge du ms. de Madrid on lit: «El autor del libro es el conde de Campomanes; adquiri en Londres el ejemplar mismo que el Conde regaló al Baron de Dylon. G." L'ami avec lequel Campomanes aurait eu ce différend serait D. Javier de Santiago 
Palomares (également en marge du ms. de Madrid).

A travers la correspondance de José Banqueri avec Cenáculo, prochainement publiée par J. L. Soto Pérez, on prend assez bien la dimension d'estime réciproque des relations Campomanes-Cenáculo, qui se matérialise par quelques rares lettres retrouvées (BPE, CXXVII/213, ASL, 200 V) et l'entrée de Cenáculo à l'Adadémie d'Histoire de Madrid. V. Léon Bourdon, art. cit. sur Juan Bautista Muhoz.

Sur les relations Bayer-Campomanes, et les frictions relatives à la réforme des Colegios Mayores, A. Mestre, «El fondo Mayáns y las corrientes interpretativas actuales de la llustración Españolan, Actes du $1 .^{\circ}$ Colloque sur le pays valencien à l'époque moderne, Pau, 1980, pp. 214215.

(73) Les noms cités ne le sont plus dans la description de la galerie de peinture du Governo Civil de Beja qui a pris la place du palais épiscopal, à l'exception de celui de Ribera, présent avec "un beau tableau" et "des copies" (Guia de Portugal [Extremadura, Alentejo, Algarve], par Raúl Proença, Lisbonne, 1917). La ville semble avoir été délaissée et abîmée par les municipalités successives. La Casa dos Corvos, par exemple, dont le dessinateur de Bayer nous offre une image belle et précise dans l'Extracto conservé à Madrid, n'existe plus, et seule sa caractéristique fenêtre manuéline peut encore être admirée au Musée Archéologique.

De la dynastie de peintres originaire de Bassano, du nom de Da Ponte, c'est Jacob, dit le Bassan, dont il est probablement question. Il y a en effet trace de tableaux de ce peintre au Portugal.

Pour ce qui est de N. Vris, el s'agit apparemment d'une erreur, car aucun peintre, pas plus portugais que d'une quelconque autre nationalité, ne semble répondre à un tel patronyme.

(74) J. Marcadé, Frei Manuel, op. cit., pp. 245-247.

(75) BPE, CXXVIII/1-2, f. ${ }^{\circ}$ 128. V. Salgado à Cenáculo, Lisbonne, 25-Xl-1782.

(76) C'est par le journal de Cenáculo qu'on apprend le nom du chanteur, car Bayer indique seulement qu'il y avait lả "un Tiple italiano que casualmente havia hido á Beja desde Lisboa». Cenáculo précise: "Lhe dei (a Bayer) huma serenata na qual cantou o italiano Todi que está aqui meo hospede ha mezes". Il ajoute qu'une épigramme a été écrite et lue en l'honneur de Bayer, détail que ce dernier rapporte avec modestie: "Tocabase una simphonia o una aria y en el intervalo el Maestro de Retorica de Palacio decia una pequeña harenga latina. Después el de Poesia recitaba un Epigrama. Todo era en elogio mio, lo que en medio de la gran merced que en ello me hacia su IIIma., me causaba gran mortificación" (Di., 129, et BPE, CXXIX/1-18, 4-XI-1782 sqq.). Ce Todi a-t-il quelque chose à voir avec la plus grande cantatrice de l'époque au Portugal, Luísa Todi?

(77) BPE, ibid.

(78) Cf. n. 26: les noms cités précisément ceux de personnes prévenues par Cenáculo de la visite de Bayer et qui urendent compte». Ainsi José Maldonado fait-il plusieurs allées et venues pour intercepter Bayer sur son chemin, sans y parvenir, et regrette-t-il de n'avoir pu lui faire accepter son hospitalité (BPE, CXXVII/2-4, n. ${ }^{\circ} 3017$ ). L'Inquisiteur Aguilar de Meneses, chez qui Bayer est reçu "avec une table mise comme pour un jour de noce" (Di., 135), baise les mains de Cenáculo, qui lui a permis de "connaître Monsr. Bayer, ecclésiastique aussi sage que pieux". II ajoute: "Vay apachonadissimo por V. Ex" "(BPE, CXXVII/1-11, n. ${ }^{\circ} 2032$ ).

(79) Journal de Cenáculo, BPE, CXXIX/1-18, 7-X|-1782: il demande à Maldonado d'offrir un concert a Bayer si tel musicien (écriture illisible) est là.

(80) José Ignácio da Rocha Peniz l'accueille tant à l'Université qu'au Collège de São Pedro, tient Cenáculo au courant et conclut pour ses collègues: "Elles se lizongeiam muito de haverem obzequiado a V. E. na pessoa do Sr. Bayer, o qual por estrangeiro nåo menos que pelas suas boas partes e notorias emprezas literarias, fazendo-se merecedor de qualquer acolhimento honorifico, com quanta razåo o deveria encontrar nesta caza de V. E. recomendando o nella o santo nome de amigo de V. E." (BPE, CXXVII/2-4, n. ${ }^{\circ}$ 2961). Est-ce à lui, est-ce à une autre autorité universitaire que Cenáculo écrit le 13 juin 1783 pour recommander Bayer? (BPE, CXXVIII/2-9, f. ${ }^{\circ} 373$, Cenáculo à ?, de Beja).

(81) BPE, CXXVIII/1-9, n. ${ }^{\circ}$ 1770. Bayer à Cenáculo, Aldeia Galega, 12-XI-1782. 
(82) L'église de S. Francisco est un des plus beaux monuments d'Evora. Très caractéristique du style gothique-morisque de l'Alentejo, c'est une immense nef de $24 \mathrm{~m}$. de haut et $36 \mathrm{~m}$. de long. Le portail combine le marbre des colonnes et des arcades manuélines avec le granit de la construction. On y remarque l'emblème de D. Joâo II, le pélican, ainsi que la sphère armillaire de D. Manuel.

(83) II s'agit de la capela dos ossos, fantaisie macabre dont on a d'autres exemples au Portugal même, ainsi qu'en Italie et en Bohême.

(84) La cathédrale d'Evora est comparable en beauté à celle de Coïmbre. Commencée au $X I I I^{\circ}$ siècle, poursuivie au XV ${ }^{\circ}$ et XVI ${ }^{\circ}$, elle sera dotée par Jean V. d'une capela-mor due à l'architecte de Mafra Ludovice. On en admire tout particulièrement les tours et la coupole centrale au dessin en écailles. Le Christ montré à Bayer est-il la grande sculpture en bois de cèdre due à Manuel Dias, appelée o pai dos Cristos?

(85) La croix d'argent aux 1426 pierres précieuses, de la fin du XVII ${ }^{\circ}$ siècle, que Bayer examine, fait aujourd'hui partie du Trésor de la cathédrale.

(86) Qu'il appelle à juste titre «de Saint Jean l'Evangéliste». Ce monastère magnifique fut construit de 1485 à 1491.

(87) On a tout à fait renoncé aujourd'hui à faire remonter cette tour à Sertorius.

(88) Belle oeuvre du XVI1० siècle, peut-être due à Filippo Terzi.

(89) BPE, CXXVIII/2-9, n. ${ }^{\circ}$ 1774. Bayer à Cenáculo, Ponte da Murcela, 1-VHI-1782.

(90) Ibid., n. ${ }^{\circ}$ 1775. Bayer à Cenáculo, Porto, 10-VII-1783.

(91) "le faltó a V. M. (V. Salgado) decirme algo de parte de las pobrecitas Morenas Assistentas à quienes yo estimo tambien à proporcion aunque no sea mas que por ser familia de una Hermana de nuestro gran Señor Obispon (ASL, 178 V, Bayer à V. Salgado, Madrid, 31-XII-1782). Aucun doute ne peut étre permis sur l'acception du mot familia, toujours employé par Bayer au sens de "personnel domestiquen. II demande encore des nouvelles des "pauvres Morenas" en 1784 (BPE, CXXVII/1-9, n. ${ }^{\circ}$ 1776. Bayer à Cenáculo, Madrid, 26-VIII).

(92) Marcadé, Frei Manuel, op. cit., p. 139, signale l'apparent désintérêt de Cenáculo pour l'esclavage, (théoriquement aboli en Métropole, il est vrai, depuis 1761), alors que l'évêque de Beja se penche, par exemple, sur le sort des ouvriers agricoles. II y avait pourtant encore de nombreux esclaves en Alentejo (environ 5.000 dans l'ensemble des provinces au sud du Tage). A Lisbonne l'afflux d'esclaves vingt ans plus tót était tel que le transport d'esclaves noirs des deux sexes depuis les ports d'Afrique, du Brésil et d'Asie avait dû être interdit par alvará à force de loi du 19 septembre 1761 (J. Veríssimo Serrão, História de Portugal (1750-1807), Ed. Verbo, Póvoa de Varzim, Cacém, 1982, p. 136). Tout acheteur, vendeur ou détenteur d'esclaves devait être puni. Mais la loi ne s'appliquait pas aux esclaves déjà installés au Portugal —dont les enfants étaient considérés par les maîtres comme "des esclaves car fils d'esclaves" (ibid.)- . Ce devait probablement être la condition de ces Morenas. Racheter un esclave qui était dans ce cas, c'était donc lui donner sa liberté, ou carta de alforria.

(93) BPE, CXXVIII/2-9, f. ${ }^{\circ}$ 393. Cenáculo à Bayer, Beja, 8-X-1784.

(94) BPE, CXXVIII/1-9, n. ${ }^{\circ}$ 1773. Bayer à Cenáculo, Madrid, 9-l-1783. Sur le Salustio, v. n. 2.

(95) "Sim Senhor, irá a Biblia de Cassiodoro Reina, e vai com muito boa vontaden (Cenáculo à Bayer, 19-1l-1783). "Vai finalmente a Biblia. Tardou porque não era decente mandar a que não tem frontispicion. (Du mẻme au méme, Beja, 7-XI-1785). BPE, CXXVIII/2-9, fos 370 et 409.

(96) BPE, CXXVIII/1-9, n. ${ }^{\circ}$ 1773. Bayer á Cenáculo, Madrid, 9-I-1783.

(97) Il existe deux autographes de cette poésie, l'un à la BNL (Cod. 3192), qui est celui adressé à R. dos Santos, l'autre à l'ASL, archivé par les soins de V. Salgado. Le premier est précédé d'une citation de Virgile, et R. dos Santos précise: aPoezia Latina de Francisco Peres Bayer, Arcediago de Valença e Mestre dos Infantes de Espanha, que de sua propria letra mandou etc.". Le second porte l'adresse: Ad Exmum Dnum Fr. Emmanuelem á Cœenáculo Episcopum Pacensem, mais le vers de Virgile n'y figure pas.

D'autre part, les premiers vers, identiques aux derniers, sont tirés de Cicéron dans les Lettres familières, ce qui nous permet d'inscrire cette amitié entre Cenáculo et Bayer dans une 
tradition, que l'orientaliste valencien prend très certainement comme modèle idéal, non sans considérer qu'il a quelque raison "d'entrer dans la carrière".

Voici le texte de cette poésie, accompagné de sa traduction:

...Vox quoque Moerin

Iam fugit ipsa...

O dudum EMMANUEL meis medullis Haerens, charior et meis ocellis, Qui dulci alloquio iocisque pleno Urbanis salibusque, literisque Doctis, Juppiter, et laboriosis, Donis praeterea cupediisque Ipsi quas superi invidere possent Et pleno et supereffluente cornu Gaza é divite me diu beasti:

$\mathrm{Hic}$ inter iuga montiumque fauces

Anfractusque viarum, et alta Stellae Caelo in Lusitaniam propinquo

Lapsae culmina, saxa amantis et refertae subere fraxino aesculoque, Sed et castaneis sacrâque vite, Ficubus quoque mitibusque pomis: Leni et murmure blandientium inter Perennes scaturigines aquarum: Dum TUAE recolo benignitatis Immo et iam pietatis argumenta Erga me, licet oppido immerentem: Hosce versiculos fluente vena Rudes illepidos et inficetos Pangebam numerisque destitutos, Fortassis pedibusque claudicantes Prae desiderio TUI, qui in ipsis Haeres EMMANUEL meis medullis Dudum charior et meis ocellis.
Déja Moeris lui-même sent sa voix le fuir. O Manuel, qui depuis longtemps habites au fond de mon cœur, toi qui m'es plus cher que la prunelle de mes yeux, toi qui, débordante corne d'abondance, m'as comblé de l'opulent trésor de tes agréables entretiens remplis d'un badinage de bon ton et de subtils traits d'esprit, mais aussi, par Jupiter, d'un docte savoir acquis par le travail -entretiens tels que les dieux eux-mêmes pourraient en désirer-, me voici parmi les sommets et les étroits défilés de la Montagne de l'Etoile qui, tombée du haut tout proche du ciel sur le sol de la Lusitanie, manifeste sans doute un certain goût pour les rochers, mais n'en est pas moins couverte de chênes-liège, de rouvres et de frênes, et aussi de châtaigniers et de vignes consacrées à Bacchus, sans oublier les figuiers et autres arbres aux fruits délectables, tous poussant autour de sources intarissables dont le doux murmure flatte nos oreilles. Et tandis que je me remémore les preuves de la bienveillance, ou plutôt de l'affection dont tu m'entoures - bien que j'en sois tout a fait indigne - je compose ces versiculets au courant de l'inspiration: ils sont sans art, sans esprit et sans gråce, ils manquent de rythme et il se peut même qu'ils boîtent, mais je les écris pour te dire combien j'ai envie de te revoir, toi, Manuel, qui depuis si longtemps habites au fond de mon cœur et qui m'es plus cher que la prunelle de mes yeux.

Et Bayer signe son nom en caractères grecs...

(98) L. Bourdon, art. cit., sur Muñoz, p. 503, n. 3, rappelle à propos du Nubiense: «Par suite d'un lapsus de copiste, un abrégé du Kitab Nuzhat ou Kitab Rudjar, célèbre traité de géographie composé au milieu du XII ${ }^{\circ}$ siècle par al-Idrisi sur l'ordre du roi Roger Il de Sicile a été attribué à un Nubien, le "Géographe nubien". II ajoute que l'édition de Rome est en arabe et qu'une traduction latine en a été effectuée par deux Maronites et publiée á Paris en 1619. Ajoutons que le $\mathrm{Nu}$ biense, traduit en espagnol par Casiri, joue un rôle dans la querelle H. Flórez-G. Mayáns à propos du Cronicón del moro Rasis. A. Mestre, Historia... op. cit., par l'index. Parmi les oeuvres de Campomanes se trouve une Traducción al castellano de la descripción de España del geógrafo árabe al-Idrisi.

(99) BPE, CXXVIII/1-2, f. ${ }^{\circ}$ 171. V. Salgado à Cenáculo, Lisbonne, 28-II-1783.

(100) BPE, CXXVIII/2-9, f. ${ }^{\circ} 370$. Cenáculo à Bayer, Beja, 19-II-1783.

(101) L. Bourdon, art. cit. sur Muñoz, pp. 503-504, n. 3. 
(102) BPE, CXXVIII/1-2. V. Salgado à Cenáculo, Lisbonne, 18-XI-1782.

(103) loid.

(104) Marcadé, Frei Manuel, op. cit., p. 228. Bayer et Cenáculo ont donc des revenus comparables, qui leur permettent des achats de livres conséquents.

(105) BPE, CXXVIII/1-9, n. ${ }^{\circ}$ 1776. Bayer à Cenáculo, Madrid, 26-VIII-1784.

(106) J. Marcadé, Frei Manuel, op. cit., p. 144. Pour l'ensemble des oeuvres de charité, id. ibid., pp. 229-234.

(107) BPE, CXXVIII/1-9, n. ${ }^{\circ}$ 1776. Bayer à Cenáculo, Madrid, 26-VIII-1784. Cette lettre contient une description de la bibliothèque de Bayer Intéressante, qui complète celle qu'il donne, par exemple, à J. A. Mayáns (Epistolario Mayáns-Pérez Bayer cit., pp. 418-420). Dans une lettre de Cenáculo à J. A. Mayáns, on a des échos du transfert à Valence de la bibliothèque de Bayer: «Felicito a V.S. I. pela generoza aquisição da Bibliotheca do Sr. Bayer. Sei grande numero de obras que elle mandou, mas Valença tudo merece, e tudo ha recebido com a dignidade de que he capaz: huma Cidade sensatissima e polidissimamente educada. Gaudeant bene nati" (B. M. Va. Serrano Morales, $6811,2 .^{\circ} \mathrm{leg} .^{\circ}$, Beja, 8-X(-1785), et l'on en a de son inauguration par la réponse de Juan Antonio: «La Libreria del Sr. Bayer se coloco con un aparato magnifico, i sonando varios instrumentos Musicos, que resonaron bien en la Gacetan, qui ajoute des commentaires peu amènes sur l'avenir de cette bibliothèque, qui sera mal entretenue dans un pays uplein de chardons", et dont les ouvrages serviront quelque jour à faire du feu pour cuire du pain” ... (BPE, CXXVIII/1-8. J. A. Mayáns à Cenáculo, Valencia, 28-II-1783, f. ${ }^{\circ} 131$ ).

(108) BPE, CXXVIII/2-9, f. ${ }^{\circ}$ 401. Cenáculo à Bayer, Beja, 8-X-1784.

(109) Ibid.

(110) Sur cette question, J. Marcadé, Frei Manuel ..., op. cit., pp. 37-38, 69-72, 240-241. La Real Biblioteca Pública da Corte est créée en 1796.

(111) B. M. Va. Serrano Morales, $6811,2{ }^{\circ}$ leg. ${ }^{\circ}$ Cenáculo à J. A. Mayáns, Beja, 18-I-1782: "Peço a V. S. a queira favorecer-me com a Reprezentação do Sñr. D. Gregorio seo dign mo Irmão, o que eu sempre reconhecerei com a minha obediencian. II redemande le portrait en mai 1783, et dit dans une lettre du 12-XI-1783, "le voir (chez lui) avec tendresse" (ibid.).

(112) BPE, CXXVIII/1-2. V. Salgado a Cenáculo, Lisbonne, 30-XII-1782, 21-1-1783 (fos 142,

(113) II semble qu'à partir de 1784 le temps ait progressivement éteint les feux de l'enthousiasme né de la rencontre entre les deux hommes, qui se rappellent l'un à l'autre à des occasions précises, comme le voyage de Muñoz au Portugal, ou le séjour de Ferreira Gordo à Madrid. It n'en empêche pas moins que les lettres sont alors prétexte à une longue et amicale mise au point sur leurs activités, la vie littéraire espagnole ou portugaise etc.

(114) L. Bourdon, art. cit. sur Muñoz, p. 490.

(115) BPE, CXXVIII/1-9, n. ${ }^{\circ}$ 1777. Bayer à Cenáculo, Madrid, 18-VIII-1790. Sur Ferreira Gordo, v. Giuseppe Carlo Rossi, Estudios sobre las letras en el siglo XVIII, Madrid, 1967. II existe à l'ASL un ms. différent, semble-t-il, du texte utilisé par G. C. Rossi, intitulé Diario da Viagem de Monsenhor Ferreira Gordo a Hespanha... 1790, qui apporte des informations complémentaires. Diverses allusions à Bayer peuvent y être relevées.

(116) Ce n'était pas là l'opinion de tous les étrangers, ct. sur ce point José Augusto França, Lisboa pombalina e o lluminismo, Bertrand, Lisbonne, 1977, p. 214. Sur l'histoire de la statue et sa signification politique, id. ibid., pp. 205-223.

(117) Construit par les Benédictins, l'imposant ensemble de São Bento, achevé en 1615 , échappa au tremblement de terre. C'est aujourd'hui le siège du Parlement, et des Archives Nationales (Torre do Tombo).

(118) São Roque fut édifiée en 1566 par les Jésuites sur les plans de Filippo Terzi. La Chapelle de São João Baptista est une des grandes réalisations architecturales de Jean V. Commandée aux architectes Vanvitelli et Nicola Salvi, elle fut inaugurée en 1750. Ludovice, l'architecte de Mafra, en revit soigneusement les plans afin de les accorder à la mission «noble, grave, 
richen d'un tel autel. Annonçant le néo-classicisme, c'est un remarquable musée de l'architecture décorative italienne de l'époque (J. A. França, op. cit. pp. 46-47) Bayer est vraiment confronté, si l'on peut dire, a trois Lisbonne, qui marquent trois états et trois étapes du Portugal des Lumières: la Lisbonne fastueuse, de l'or et des diamants du Brésil, qui s'incarne en João $V$ et connaît son apogée à Mafra, la Lisbonne rationnelle, soumise à un schéma urbanistique fonctionnel, dont la statue équestre règle les destins, enfin la Lisbonne post-pombaline, qui semble avoir pour seule option artistique l'opposition au style antérieur, et dont le maniérisme, le "rocaille" s'expriment avec verve à Queluz, fantaisie coûteuse et inutile du prince consort.

(119) Les femmes n'étaient pas autorisées à se produire sur la scène, ce qui entraîna la vogue des castratti, qui chantaient aussi bien la musique profane que religieuse, les deux genres se trouvant d'ailleurs étrangement confondus à l'époque.

(120) Jommelli est un musicien italien né à Anvers en 1714, formé à l'école napolitaine et auteur de quelque cinquante opéras, Très apprécié au Portugal, il refusa toutefois de s'y rendre, mais accepta en 1769 une pension annuelle du roi José I de 1.000 escudos annuels, qui lui était concédée en échange de la promesse qu'il enverrait à Lisbonne copie de toutes ses oeuvres jusqu'à sa mort qui survint en 1774. A noter que Beckford entend cette même messe (Journal, 40).

(121) L'église du Santíssimo Coração de Jesus est plus souvent appelée Basilica da Estrela. Elle fut construite de 1779 à 1790 en accomplissement d'un voeu de D. Maria I. J. A. França $o p$. cit., p. 182, analyse subtilement les raisons qui font de ce monument érigé après la disgrâce de Pombal une réalisation caractéristique des options urbanistiques du Marquis, non sans que des signes de maniérisme à la Queluz, palais édifié par le prince consort D. Pedro, et Aventin de l'aristocratie mécontente, n'y soient aisément décelables.

(122) Il s'agit là encore d'une église due à Mateus Vicente, l'un des grands architectes pombalins, né en 1706. Formé par la construction de Mafra, il sera le dessinateur de Queluz. L'église de Santo António da Sé témoigne, selon J. A. França, d'une certaine originalité par rapport au style rectiligne de ses contemporaines, par son fronton aux lignes sinueuses et ses ornementations que font penser au baroque italien (op. cit., p. 181). Elle ne fut terminée qu'en 1812.

(123) La tour et la croisée du transept s'effondrèrent avec une partie des voûtes. On peut apprécier l'étendue du désastre en considérant la célèbre estampe de Le Bas en 1756.

(124) L'église patriarcale de Lisbonne reconstruite apres le tremblement de terre, en 1757, brûla douze ans après, et le siège en fut transféré à São Vicende Fora, l'un des édifices religieux les plus imposants de Lisbonne. La façade caractéristique du XVIII ${ }^{\circ}$ siècle, offre en effet diverses niches abritant des statues de saints. Elles n'ont pas l'heur de plaire à Bayer, cependant que Murphy paraît les apprécier. Le Valencien est certainement peu ami du siècle passé.

(125) II s'agit d'inscriptions du plus haut intérêt pour les spécialistes, et que l'on peut suivre "à la tracen, avant et après le tremblement de terre. En effet, l'auteur du premier "spectateur» péninsulaire, un hebdomadaire portugais des années 1752 à 1754 du nom de $O$ Anónimo, leur consacra deux numéros, engageant une discussion avec ses lecteurs, dont Tomás Caetano de Bem, ami de Mayáns. Sánchez en copia quelques unes, et elles figurent au C. I. L. Voir à ce sujet Luís Pastor de Macedo, O terremoto de 1755 na freguesia da Madalena, Lisboa, Solução Ed. s. d. 16 p. et, du même auteur $A$ rua das Pedras Negras, Miscelånea, Lisbonne, 1931, 137 p. Et aussi M. H. Piwnik, O Anónimo, journal portugais du XVII/ ${ }^{\circ}$ siècle (1752-1754), Paris, Fundação Calouste Gulbenkian, 1979, 603 p., pp. 383-392, 489-494, et art. cit. sur le Voyage, p. 31, pp. 53-67.

(126) Le Couvent de San Caetano ou dos Clérigos Teatinos da Divina Providencia, édifié en 1653, eut de célébres professeurs, comme Rafael Bluteau et Caetano de Bem.

(127) Les anciennes douanes étaient magnifiques et sont longuement décrites dans les ouvrages sur Lisbonne antérieurs au tremblement de terre. Elles furent détruites par le séisme, et, en attendant leur reconstruction, peú ou prou au mẻme endroit, furent placées dans des magasins provisoires en bois, qui brûlèrent en 1764. Ne restait donc, au moment de la visite de Bayer, que le quartier des anciennes douanes (Alfandega Velha, nom d'une rue et d'une impasse situées dans les parages) - selon toutes probabilités-, où des pierres présentaient les inscriptions qu'il relève. Dans le Journal (p. 151) il précise que la Bibliothèque de la Real Mesa Censória se trouvait en la misma Alfandega Velha. La seule indication que nous ayons relevée à ce sujet, 
qui n'éclaire guère les choses est la suivante (Guia de Portugal, op. cit. vol. Lisboa): «(a Biblioteca Nacional de Lisboa) ocupou primeiramente o edifício que desde 1775 pertencia a livraria da Mesa Censória no segundo pavimento da arcada Oeste do Terreiro do Paço, onde é hoje a direç̧ăo geral da estatístican. Or les douanes, tant anciennes que nouvelles, ont toujours été à l'Est, les bureaux en étant situés dans l'aile Ouest de cet emplacement... Le couvent de Nossa Senhora de Jesus appartenait au Tiers-Ordre franciscain depuis 1615. Très abìmé par le tremblement de terre, il fut reconstruit sous impulsion Cenáculo (V. J. Marcadé, «D. Fr. Manoel do Cenáculo, Provincial des Réguliers du Tiers-Ordre Franciscain de la Province de Portugal, 1768-1777", Arquivos do Centro Cultural Português, III, 1971, pp. 431-458). II devint par la suite le siège de l'Acadèmie des Sciences, ce qui n'est pas sans valeur symbolique.

(128) BPE, CXXVIII/1-2, f. 142. V. Salgado à Cenáculo, 2-XII-1782.

(129) Ce musée était installé à Junqueira, et était considéré comme l'une des curiosités de la Lisbonne de l'époque.

(130) D. Juan de Santander.

(131) BPE, CXXVII/1-9. Bayer à Cenáculo. Madrid, 26-VIII-1784. Cenáculo devait écrire et publier en 1791 une oeuvre d'érudition réunissant ses connaissances sur divers aspects de la culture portugaise du XVI ${ }^{\circ}$ siecle, Cuidados Literarios do Prelado de Baja em graça do seu Bispado, Lisboa. V. à ce sujet F. da Gama Caeiro, Frei Manuel op. cit. pp. 98-107.

(132) BPE CXXVIII/1-2, f. ${ }^{\circ}$ 128. V. Salgado à Cenáculo, Lisbonne, 25-XI-1782.

(133) Ibid. Dans la bibliographie d'A. Pereira de Figueiredo, quatre titres font référence à ces «choses de la Cour". Le premier est ce Parallelo, Lisboa, Regia Officina Typographica, 1775, fol. de $36 \mathrm{p}$. On trouve ensuite Breve discurso sobre a reedificaçăo de Lisboa, e sobre a dedicação da Estatua Regia, dirigido ao Marquez de Pombal no dia dos seus annos. 13-V-1776. Lisboa, Regia Officina Typographica. Escripto em portugués e latim. $16 \mathrm{p}$. La brochure s'intitulait-elle en latin Statua Vocalis? II n'y a aucune oeuvre de ce titre dans le recensement d'Inocéncio, qui signale ensuite $O$ dia das tres inaugurações. Breve discurso sobre a regia funcção do dia 6 de junho de 1775 (...) ao Conde de Oeiras. Fol. Lisboa, Regia Officina Typographica, 1775, et Preces e votos da Nação Portuguesa ao Anjo da Guarda do Marquez de Pombal, ibid., même imprimeur, même date, 17 p. Continuer leur diffusion en 1782, et auprès d'un étranger, montre l'accueil fait par des gens comme P. de Figueiredo, Cenáculo, ou Salgado, au régime de D." Maria I.

(134) Ibid.

(135) Ibid., f. ${ }^{\circ}$ 142. V. Salgado à Cenáculo, Lisbonne, 2-XII-1782.

(136) Ibid., f. ${ }^{\circ}$ 128. V. Salgado à Cenáculo, Lisbonne, 25-XI-1782.

(137) Sur cette question, outre l'art. cit. de F. da Gama Caeiro, v. Geoges Bonnant, "L'imprimerie à Genève du XV' au XVIII ${ }^{\circ}$ siècle et le commerce des libraires genevois avec le Portugal", Arquivo de Bibliografia Portuguesa, II, 1956, pp. 1-16, et "Les libraires du Portugal au $X V I I I^{\circ}$ siècle vus à travers leurs relations d'affaires avec leurs fournisseurs de Genêve, Lausanne et Neuchâteln, ibid., VI, 1960, n. ${ }^{\circ}$ 23-24, pp. 195-200. V. aussi Angela Maria do Monte Barcelos da Gama, "Livreiros, editores e impressores em Lisboa no século XVIIl», ibid., Ano 13, núms. 49, 52. 1967, 1968.

M. le Beux est súrement Claude du Beux ou Dubeux, dont est conservée à Evora une correspondance avec Cenáculo.

(138) D'après Marcadé, Frei Manuel, p. 229, José Reycend vécut vingt ans à LIsbonne avant de s'établir à Turin. Les Borel en auraient été les représentants dans la capitale portugaise. Les lettres dont fait état Marcadé, qui toutes ont trait à des dettes de Cenáculo auprès de divers libraires, dont Reycend, sont de 1792 et 1795, donc largement postérieures au voyage de Bayer, ce qui permet effectivement d'envisager un déménagement -ou un retour au bercailde Reycend.

(139) Gonzalo Argote de Molina, Historia de la nobleza de Andalucia. 1588.

(140) Joannes Dameto, Historia del Reyno balearico. Nicolás Antonio précise (Bib. Hispana Nova, I, 682): Joannes Dameto Majoricensis juris utriusque doctor, regni sui chronographus, 
scripsit diligenter Historia General del Reino Balearico. Majoricae apud Gasparem Guasp. 1633 in fol. Pertinet haec usque ad annum MCCCXI sive mortem Jacobi II. Majoricarum Regis: reliqua desiderant.

(141) Las Tres corónicas, relatives aux règnes de Alfonso XI, Sancho IV et Fernando IV, sont généralement attribuées au Canciller Fernán Sánchez de Valladolid (B. Sánchez Alonso, Historia de la historiografia española, Madrid, C. S. I. C., 1941).

(142) Moisés Almosnino, fils de Baruch, rabbin de Salonique, né en 1523, est connu pour les ouvrages Yede Moschech et Pene Moschech.

(143) Evoquant les oeurres «monstrueuses et pédantesques» qui marquent la décadence du roman de chevalerie, Menéndez Pelayo dans Origenes de la novela ajoute que l'un de ces derniers soubresauts est la Historia famosa del príncipe d. Policisne de Beocia, hijo y único heredero de los reyes de Beocia Minandro y Grumudela, de Juan de Silva y Toledo, señor de Cañadahermosa. Valladolid, 1602.

(144) Libro de la Vida Santa y milagros del llustrissimo y Reverendissimo Señor D. Fr. Tomas de Villanueva, Arzobispo de Valencia de la orden de S. Agustin. Valentiae 1588 et 1620, par Fr. Michael Bartholomeus Salon (Bib. Nova, III, 131).

(145) Selon Menéndez Pelayo, op. cit., p. 416, le Palmerín de Oliva (1 ${ }^{2}$ ed. 1511) manque d'originalité et est une copie servile d'Amadis. Quant à l'autre: «Sólo por la circunstancia de es. tar mencionado en el Quijote hay todavia quien recuerde el Don Girongilio de Tracia de Bernardo Vargas (1545)" (p. 437).

(146) BPE, CXXVIII/1-2, f. ${ }^{193}$. V. Salgado à Cenáculo, Lisbonne, 22-IV-1783. Les Carreño sont courriers de père en fils.

(147) BPE, CXXVIII/1-9, n. ${ }^{\circ}$ 1773. Bayer à Cenáculo, Madrid, 9-1-1783.

Sempere y Guarinos, op. cit. art. cit. Bayer, commente longuement l'ouvrage Damasus et Laurentius Hispanis asserti et vindicati. Rome, 1756.

(148) lbid., n. ${ }^{\circ}$ 1776. Bayer à Cenáculo. Madrid, 26-VIII-1784.

(149) Pour une approche théorique de la spécifité des Lumières ibériques, v. pour l'Espagne François Lopez, "Rasgos peculiares de la Ilustración en España», Simposio Mayáns y la Ilustración, Ayuntamiento de Oliva, 1982, pp. 629-671.

(150) ASL, Mss. 172 V. Cenáculo à R. Mohedano, Lisbonne, 7-IV-1767.

(151) BPE, CXVIII/1-9, n. ${ }^{0} 1772$. Bayer à Cenáculo, Lisbonne, 25-XI-1782.

(152) A propos de la fortune de la Tentativa en Espagne, v. de premières indications in M. H. Piwnik, "Images de la culture pombaline dans l'Espagne des Lumières» Revista de Historia das ldeias, Coimbra (à paraître).

(153) Outre art. cit. sur Muñoz, v. également de L. Bourdon, José Corrêa da Serra Ambassadeur du Royaume Uni de Portugal et Brésil à Washington 1816-1820, Fundação Calouste Gulbenkian, Centre Culturel Portugais, Paris, 1975, 668 p.

(154) A son sujet, consulter son éloge funèbre à l'Académie des Sciences de Lisbonne, Memorias da Academia, t. IV, parte 1. ${ }^{\mathrm{a}}$, XLIV sqq. Et aussi les art. cit. de Soto Pérez sur Banqueri et de M. H. Piwnik sur "Les membres portugais de l'Académie etc.".

(155) Entre 1729 et 1748 , à grands frais.

(156) L'arrivée à Mafra avait été plutôt chaotique. C'était jour de foire, et la place devant le Monastère était "une véritable Babylone»: «Paños, lienzos, suelas, pieles, frutas, pan, vino, em. panadas 6 pasteles, y otros mil comestibles. Havia tambien charlatanes, sacamuelas, juegos de manos y otras habilidades». Dans cette confusion, Bayer tente d'apprécier l'édifice construit par João V, l'estimant "un peu plus grand que l'Escurial" et souvent comparable à Saint Pierre de Rome. Voulant en faire un dessin, même approximatif, il s'engage dans un espace découvert qui fait le tour de l'église, ayant trouvé une grille ouverte. Mais il lui est impossible de ressortir, cette grille, et toutes les autres issues ayant été fermées par une main diligente. Sans perdre son sang-froid, el essaie de se faire délivrer, n'y parvenant qu'au bout de trois quarts d'heure: "puseme como los presos Ilamando a quantos pasaban. Eran casi todos gentes de aquellas aldeas 
que tenian atadas sus bestias a las verjas de la puerta (...) Ellos ni bien me entendian, y tenian más cuidado de irse á sus casas (...) Vino al fin uno que me dixo tuviesse paciencia: era de ropage pobre: ofrecile que le gratificaria su trabajo; buscó y trajo consigo sugeto que me abrió y sacó del encierro. Paguéle mi carcelajen (Di., 165).

(157) Brouillon de lettre de Campomanes à Pombal conservé à la Fundación Universitaria Española (Catálogo Cejudo López, 34-5), où il commente dans le détail l'ensemble des Statuts dont les trois volumes lui ont été envoyés par Pagliarini, Directeur de l'Imprimerie Royale de Lisbonne -curieuse figure dont on aura à reparler-. La lettre porte la date du 31-XII-1772 (Madrid). $Y$ est jointe la lettre en italien de Pagliarini à Campomanes, Lisbonne, 8-XI1-1772. Campomanes donne également son point de vue sur les Statuts à Cenáculo (BPE, CXXVII/2-13). Rafael Mohedano rédige lui aussi ses impressions à l'adresse de Cenáculo (ASL, Ms. $200 \mathrm{~V}$ ). Mayáns attendait les Statuts avec impatience, mais Pingarrón les a gardés par devers lui pour en tirer copie, probablement à cause de "la passion que no puede dissimular a la Gente Social" (BPE, CXXVIII/1-8. Valencia, 8-II-1773, à Cenáculo). II en fait d'amples compliments un an après (Ibid. Valencia 26-IV-1774, au même).

(158) BPE, CXXVIII/2-9, f. ${ }^{\circ}$ 373. Cenáculo à ?. Beja, 13-VI-1783.

(159) BPE, CXXVIII/1-9, n. ${ }^{\circ}$ 1775. Bayer à Cenáculo, Porto, 10-VII-1783. 1783.

(160) BPE, CXXVII/2-4, n. ${ }^{\circ}$ 2960. José Ignácio da Rocha Peniz à Cenáculo, Coimbra, 21-VII-

(161) BPE, CXXVIII1-9. Bayer à Cenáculo, Porto, 10-VII-1783.

(162) BPE, CXXVII/2-4, n. ${ }^{\circ}$ 2960. Rocha Peniz à Cenáculo, Coimbra, 21-VII-1783.

(163) Ibid.

(164) BPE, CXXVIII/1-9; Bayer à Cenáculo, Porto, 10-VII-1783.

(165) BPE, CXXVII/2-4, n. ${ }^{\circ}$ 2960. R. Peniz à Cenáculo, Coimbra, 21-VIl-1783. II ne s'agit pas du Colégio de São Pedro qui se trouve contre I'Université, mais du Colégio du même nom qui était situé à côté du Colégio da Graça, et fut donné au Tiers-Ordre lors du transfert de ses premiers occupants dans le Colégio de l'Université précisément.

(166) BPE, CXXVIII/1-9, n. ${ }^{\circ}$ 1775. Bayer à Cenáculo, Porto, 10-VII-1783.

(167) V. le long article qui lui est consacré par Inocêncio, Dicionário Bibliográfico Português, à António Ribeiro dos Santos.

(168) Thomas de Villanueva naît à Fuenliana (Ciudad Real). Ce "père des pauvres" fait ses études à Alcalá et prend l'habit de Saint-Augustin. II sera archevêque de Grenade, puis de Valence. On le considère comme l'un des fundateurs de l'ascétisme en Espagne.

(169) BNL, Cod. 6796. Bayer à R. dos Santos, Porto, 11-VII-1783.

(170) Ibid. Bayer à R. dos Santos, Madrid, 19-VIII-1790.

(171) Ibid.

(172) Les lettres de Cornide à $R$. dos Santos sont en effet le même dossier que les deux de Bayer à la BNL. 